\title{
GOCO06s - a satellite-only global gravity field model
}

\author{
Andreas Kvas ${ }^{1}$, Jan Martin Brockmann ${ }^{2}$, Sandro Krauss ${ }^{1,5}$, Till Schubert ${ }^{2}$, Thomas Gruber ${ }^{3}$, \\ Ulrich Meyer $^{4}$, Torsten Mayer-Gürr ${ }^{1}$, Wolf-Dieter Schuh ${ }^{2}$, Adrian Jäggi ${ }^{4}$, and Roland Pail ${ }^{3}$ \\ ${ }^{1}$ Institute of Geodesy, Graz University of Technology, Steyrergasse 30/III, 8010 Graz, Austria \\ ${ }^{2}$ Institute of Geodesy and Geoinformation, University of Bonn, Nußallee 17, 53115 Bonn, Germany \\ ${ }^{3}$ Astronomical and Physical Geodesy, Technical University of Munich, \\ Arcisstraße 21, 80333 Munich, Germany \\ ${ }^{4}$ Astronomical Institute, University of Bern, Sidlerstrasse 5, 3012 Bern, Switzerland \\ ${ }^{5}$ Austrian Academy of Sciences, Space Research Institute, Schmiedlstraße 6, 8042 Graz, Austria
}

Correspondence: Andreas Kvas (kvas@tugraz.at)

Received: 13 July 2020 - Discussion started: 12 August 2020

Revised: 1 December 2020 - Accepted: 9 December 2020 - Published: 27 January 2021

\begin{abstract}
GOCO06s is the latest satellite-only global gravity field model computed by the GOCO (Gravity Observation Combination) project. It is based on over a billion observations acquired over 15 years from 19 satellites with different complementary observation principles. This combination of different measurement techniques is key in providing consistently high accuracy and best possible spatial resolution of the Earth's gravity field.

The motivation for the new release was the availability of reprocessed observation data for the Gravity Recovery and Climate Experiment (GRACE) and Gravity field and steady-state Ocean Circulation Explorer (GOCE), updated background models, and substantial improvements in the processing chains of the individual contributions. Due to the long observation period, the model consists not only of a static gravity field, but comprises additionally modeled temporal variations. These are represented by time-variable spherical harmonic coefficients, using a deterministic model for a regularized trend and annual oscillation.

The main focus within the GOCO combination process is on the proper handling of the stochastic behavior of the input data. Appropriate noise modeling for the observations used results in realistic accuracy information for the derived gravity field solution. This accuracy information, represented by the full variance-covariance matrix, is extremely useful for further combination with, for example, terrestrial gravity data and is published together with the solution.

The primary model data consisting of potential coefficients representing Earth's static gravity field, together with secular and annual variations, are available on the International Centre for Global Earth Models (http://icgem.gfz-potsdam.de/, last access: 11 June 2020). This data set is identified with the following DOI: https://doi.org/10.5880/ICGEM.2019.002 (Kvas et al., 2019b).

Supplementary material consisting of the full variance-covariance matrix of the static potential coefficients and estimated co-seismic mass changes is available at https://ifg.tugraz.at/GOCO (last access: 11 June 2020).
\end{abstract}




\section{Introduction}

Global models of Earth's static gravity field are crucial for geophysical and geodetic applications. These include oceanography (e.g., Knudsen et al., 2011; Rio et al., 2014; Johannessen et al., 2014; Bingham et al., 2014), tectonics (e.g., Johannessen et al., 2003; Ebbing et al., 2018), or establishing global reference and height systems (e.g., Rummel, 2013; Gerlach and Rummel, 2013). A special class of global gravity field models consists of the models derived solely from satellite observations. In contrast to terrestrial observations - which are generally sparse and collected by various instruments in different quality levels and samplings - satellite observations typically cover the entire Earth's surface. As the measurements are captured with the same sensor platform, the global accuracy level of the observations is much more consistent compared to terrestrial observations. This also alleviates adequate stochastic modeling at the observation level (Ellmer, 2018; Schubert et al., 2019) to subsequently provide uncertainty information for the derived gravity field.

The era of dedicated gravity field satellite missions (Rummel et al., 2002) provided a huge set of observations of the static as well as time-variable gravity field. The satellite orbits are sensitive to the long wavelength of the gravity field (e.g., Montenbruck and Gill, 2000; Rummel et al., 2002). They are either determined from ground by satellite laser ranging (SLR) or from space via the tracking of a lowEarth orbiter (LEO) with the satellites of the Global Position System (GPS) constellation. The laser tracking of highflying SLR satellites is sensitive only for the longest wavelengths but allows us to observe the temporal variations as well (e.g., Maier et al., 2012; Sośnica et al., 2015; Bloßfeld et al., 2018). The CHAllenging Minisatellite Payload satellite mission (CHAMP, Reigber et al., 1999) was the first dedicated gravity field mission tracked by GPS. Since then multiple other dedicated and non-dedicated satellites equipped with GPS receivers have been used to derive static and temporal gravity field models of the Earth (e.g., Bezděk et al., 2016; Lück et al., 2018; Teixeira da Encarnação et al., 2016) in this so-called satellite-to-satellite tracking in SST highlow (SST-hl) configuration.

Although SST-hl is sensitive to shorter wavelengths due to the generally lower satellite altitude compared to SLR, the spatial resolution is still limited. With the Gravity Recovery and Climate Experiment (GRACE) twin satellite mission launched in 2002 (Tapley et al., 2004, 2019), inline satelliteto-satellite tracking (SST low-low, SST-11) was established. This then novel measurement principle relies on very precise measurements of inter-satellite distance variations between a leading and a trailing satellite in the same orbit. While GRACE is dedicated to observe temporal changes in Earth's gravitational field, typically in the form of monthly snapshots (e.g., Rummel et al., 2002; Tapley et al., 2004; Mayer-Gürr, 2006; Q. Chen et al., 2018; Beutler et al., 2010), accumulat- ing observations over a longer time span allows us to derive a mean (static) gravity field. After the end of the mission in 2017, the GRACE Follow-On mission has continued the observations since 2018 (Kornfeld et al., 2019; Landerer et al., 2020), following the same design principle.

To increase the spatial resolution, tailored to the requirements of geodetic, geophysical and oceanographic applications, the Gravity field and steady-state Ocean Circulation Explorer (GOCE) mission (Battrick, 1999; Floberghagen et al., 2011) was realized and launched in 2009. In addition to SST-hl, a gradiometer served for the first time as a core instrument to measure the second derivatives of the Earth's gravitational potential in gradiometer reference frame (Rummel and Colombo, 1985; Rummel et al., 2002; Rummel et al., 2011b; Johannessen et al., 2003). Due to the design of the instrument (Stummer et al., 2012; Siemes et al., 2012, 2019), only four out of the six derivatives of the Marussi tensor could be measured with high precision $\left(V_{X X}\right.$, $V_{X Z}, V_{Y Y}$ and $\left.V_{Z Z}\right)$. Due to the measurement of the second derivatives, the spatial resolution can be increased at the cost of more complex noise characteristics. Since the determination of the long-wavelength signal is not accurate enough for time-variable gravity inversion, the focus of GOCE is on the static gravity field. In the same fashion as for the other missions, multiple expert groups perform gravity field recovery with different processing strategies (e.g., Pail et al., 2011; Farahani et al., 2013; Migliaccio et al., 2011; Brockmann et al., 2014; Schall et al., 2014; Yi, 2012).

Within typical processing workflows, mission (or technique) specific gravity field models are derived by techniquespecific experts and published as mission/technique-only gravity field models. These models are published in terms of a spherical harmonic expansion and reflect the state-ofthe-art analysis. Nowadays, these models are more often equipped with a full covariance matrix, which reflects the error structure specific to the analysis and observation technique (e.g.,Brockmann et al., 2014; Bruinsma et al., 2014; Mayer-Gürr et al., 2018a; Kvas et al., 2019a).

With a full covariance matrix in combination with a solution vector, the original system of normal equations can be reconstructed. Together with additional meta-information, such as the number of observations and the weighted square sum of the observation vector, multiple gravity field solutions can be used to derive combined gravity field models. As long as the observations used are statistically independent, the solution is the same as when starting from the raw observations. Combining multiple observation principles and satellite missions (LEOs, GRACE, GOCE and SLR) has the advantage that possible weaknesses of the individual contributions can be compensated for. However, for a proper relative weighting, it is essential that the individual models used provide a realistic error description in form of the covariance matrix of the spherical harmonic coefficients. In the case of satellite-only gravity field models, which are currently given to at most degree 300, SLR typically dominates the very long 
wavelengths (degree 2 to 5), the medium wavelengths are mainly determined by GRACE (up to degree 130) and GOCE is the main contributor to the medium to short wavelengths (degree 130 to 300) (e.g., Pail et al., 2011; Maier et al., 2012; Yi et al., 2013).

Primary focus of combined models is the static gravity field (e.g., Pail et al., 2010; Farahani et al., 2013; Yi et al., 2013); nevertheless, some of the more recent models also incorporate temporal variations, for example (piecewise) linear trends or annual oscillations (e.g., Rudenko et al., 2014). Since 2011, various models and approaches combining mainly GRACE and GOCE have been published. Whereas Farahani et al. (2013) did a joint least-squares analysis of GRACE and GOCE observations spending a lot of effort on the stochastic modeling of the observations, Yi et al. (2013) combined their self-computed GOCE normal equations with the publicly available ITG-Grace2010 model.

A specific and updated series of combined satellite-only models is provided by the EIGEN-*S series which started as a pure CHAMP-only model (Reigber et al., 2003) and turned to a GRACE, GOCE and SLR combination model in the latest EIGEN-6S release (Förste et al., 2016). These models are closely related to the GOCE solutions determined with the direct approach, which are already combination models (Bruinsma et al., 2014, 2013). Basically, GRACE normal equations processed by CNES/GRGS (Bruinsma et al., 2010) or GFZ (Dahle et al., 2019) are combined with GOCE normal equations assembled with the so-called direct approach (Bruinsma et al., 2014; Pail et al., 2011) and SLR normal equations. The combination is performed on the normal equation level. To counteract the non-perfect stochastic modeling in the GRACE, GOCE and SLR analysis, the combination is performed only for certain manually chosen degree ranges, which are selected according to the strengths of the individual techniques.

This paper continues the global satellite-only models of the GOCO*s series, which are produced by the Gravity Observation Combination (GOCO) consortium (http://www. goco.eu, last access: 20 January 2021). Since 2010, a series of satellite-only models (Pail et al., 2010) have been computed by the group, which is composed by experts on SST-hl, GRACE, GOCE and SLR-based gravity field determination. The GOCO models combine the GRACE models produced by the Graz University of Technology (previously ITG Bonn, now ITSG series, Mayer-Gürr et al., 2018b; Kvas et al., 2019a) with the time-wise GOCE normal equations (Brockmann et al., 2014), SST-hl normal equations of several LEOs (Zehentner and Mayer-Gürr, 2016) and since the second release GOCO02S SLR normal equations (Maier et al., 2012). Within the assembly of all the individual models used, a lot of effort is spent on the data-adaptive stochastic modeling of the observation error characteristics. Consequently, all input models come along with a realistic covariance matrix and are thus well suited as input for the applied combination procedure.
GOCO satellite-only models are widely used and accepted as state of the art by the community. The models published so far $(\mathrm{GOCO} 01 \mathrm{~s}, \mathrm{GOCO} 2 \mathrm{~s}$, GOCO03s, and GOCO05s) were used in a wide range of applications, for example, for global and local high-resolution models (e.g., Huang and Véronneau, 2013; Pail et al., 2016, 2018; Klees et al., 2018; Slobbe et al., 2019), geophysical studies (e.g., Rummel et al., 2011a; Abrehdary et al., 2017; W. Chen et al., 2018), oceanographic studies (e.g., Farrell et al., 2012; Siegismund, 2013), or geodetic height unification (e.g., Vergos et al., 2018).

Within this contribution, the latest release - GOCO06S (Kvas et al., 2019b) - is presented. For that purpose, the data used to estimate the global satellite-only model are discussed in Sect. 2. Section 3 covers the parametrization, which was used to describe the gravity field as well as its temporal changes. Furthermore, the applied methods are discussed. The properties of the final estimate are discussed in Sect. 4 and validated with state-of-the-art concepts. Section 6 summarizes the main characteristics of the model and presents some conclusions following from the analysis.

\section{Data sources and background models}

\subsection{Gravity field and steady-state Ocean Explorer (GOCE)}

The GOCO models make use of the normal equations of the time-wise gravity field models (e.g., Pail et al., 2011; Brockmann et al., 2014). They are independent of any other gravity field information and only contain measurements collected by GOCE. Furthermore, due to the use of an advanced stochastic model for the gravity gradients during the assembly of the satellite gravity gradient (SGG) normal equations, the formal errors are a realistic description of the uncertainties, which is beneficial for the combination procedure.

Within GOCO06s, normal equations from the time-wise RL06 model (GO_CONS_EGM_TIM_RL06, Brockmann et al., 2019; Brockmann et al., 2021) are used, which are based on SGG observations of the latest reprocessing campaign in 2019. A single unconstrained normal equation assembled from the $V_{X X}, V_{X Z}, V_{Y Y}$ and $V_{Z Z}$ gravity gradient observations up to spherical harmonic degree 300 enters the computation of GOCO06s (see Sect. 3).

Due to the sensitivity of the gravity gradients and their spectral noise characteristics, normal equations are assembled only with respect to the static part of the Earth's gravity field. To define a clear reference epoch and being consistent with the GRACE processing, the time-variable gravity signal was reduced from the along-track gravity gradient observations in advance. For this purpose, the models as summarized in Table 1 were used to refer the observations (and thus the right-hand side $\boldsymbol{n}_{\mathrm{SGG}}$ to the reference epoch 1 January 2010). 
Table 1. Models used to reduce the temporal gravity changes.

\begin{tabular}{lll}
\hline Force & Model & Reference \\
\hline Earth's gravity field (annual oscillation and trend) & GOCO05s & Mayer-Gürr et al. (2015) \\
$\begin{array}{l}\text { Non-tidal atmosphere and ocean variations } \\
\text { and atmospheric tides }\end{array}$ & AOD1B RL06 & Dobslaw et al. (2017) \\
Astronomical tides (Moon, Sun, planets) & JPL DE421 & Folkner et al. (2009) \\
Solid Earth tides & IERS2010 & Petit and Luzum (2010) \\
Ocean tides & FES2014b & Carrere et al. (2015) \\
Pole tides & IERS2010, linear mean pole & Petit and Luzum (2010) \\
Ocean pole tides & Desai (2002), linear mean pole & Desai (2002) \\
\hline
\end{tabular}

It enters the combination procedure (see Sect. 3) as a normal equation system of the form

$\mathbf{N}_{\mathrm{GOCE}} \hat{\boldsymbol{x}}_{\mathrm{GOCE}}=\boldsymbol{n}_{\mathrm{GOCE}}$,

where $\hat{\boldsymbol{x}}_{\mathrm{GOCE}}$ is the vector of unknown static spherical harmonic coefficients, and $\mathbf{N}_{\mathrm{GOCE}}$ and $\boldsymbol{n}_{\mathrm{GOCE}}$ are the normal equation coefficient matrix and right-hand side respectively. This system of normal equations is given in a predefined ordering for the GOCE contribution (spherical harmonic degrees 2 to 300). This single normal equation already contains the stochastic models used in the time-wise processing (cf. Schubert et al., 2019), the relative weighting of the different gravity gradients and the different time periods of observations. It is the same normal equation as used in GO_CONS_EGM_TIM_RL06, which is in the context of a GOCE-only model combined with SST-hl data and constrained (cf. Brockmann et al., 2021).

\subsection{Gravity Recovery and Climate Experiment (GRACE)}

The GRACE contribution to GOCO06s consists of a subset of the normal equations of ITSG-Grace2018s (MayerGürr et al., 2018; Kvas et al., 2019a). Similarly to the GOCE normal equations, ITSG-Grace2018s features a full stochastic model of the inter-satellite range rates used and hence provides realistic formal errors. The normal equations used incorporate GRACE data in the time span of April 2002 to August 2016, because at the time of the computation the reprocessed observation data (GRACE, 2018) for the single-accelerometer months starting from September 2016 to June 2017 were not yet publicly available. The normal equations feature a static part parametrized up to degree/order 200 and secular and annual variations up to degree/order 120 . The background models used in the processing of the GRACE data are consistent with the GOCE contribution (see Kvas et al., 2019a, for details). The normal equations

$\mathbf{N}_{\text {GRACE }} \hat{\boldsymbol{x}}_{\mathrm{GRACE}}=\boldsymbol{n}_{\mathrm{GRACE}}$

are computed in monthly batches and then accumulated over the observation time span. Due to the high sensitivity of
GRACE to the longer wavelengths of the spherical harmonic spectrum, it is the primary contributor to the temporal variations.

\subsection{Kinematic orbit of low-Earth orbit (LEO) satellites}

For GOCO06s, we made use of kinematic orbit positions from nine satellites. In addition to GRACE A/B (see Sect. 2.2), these include CHAMP, TerraSAR-X, TanDEM-X, GOCE and SWARM A+B + C. The kinematic orbit positions were computed using precise point positioning following the approach of Zehentner and Mayer-Gürr (2016). The normal equations $\mathbf{N}_{k}^{(s)}, \boldsymbol{n}_{k}^{(s)}$ for gravity field determination were assembled using the short-arc approach (Mayer-Gürr, 2006; Teixeira da Encarnação et al., 2020) in monthly batches for each satellite $s$ and epoch $k$. For CHAMP, GRACE, TerraSAR-X, TanDEM-X and SWARM we set up the normal equations up to degree and order 120, while for GOCE, due to the lower orbit altitude and the subsequent higher sensitivity, the normal equations were assembled up to degree and order 150. For all LEO satellites except GRACE, only the static gravity field was modeled. We made the decision to not include secular and annual variations in the parameter set based on practical considerations. Even though SST-hl has skill in determining the time-variable gravity field, the expected contribution of the LEO orbits to the temporal constituents, with the presence of GRACE inter-satellite-ranging observations and SLR, will be low. That results in a steep trade-off between the increase in solution quality and the computational demands required to set up the additional parameters. Since we applied an appropriate stochastic model in the assembly of the systems of normal equations, the relative weighting between the satellites and epochs is already contained in the normal equations. Therefore, we only need to accumulate all satellites and months, as

$\mathbf{N}_{\text {LEO }}=\sum_{k} \sum_{s} \mathbf{N}_{k}^{(s)}, \quad \boldsymbol{n}_{\text {LEO }}=\sum_{k} \sum_{s} \boldsymbol{n}_{k}^{(s)}$.

The kinematic orbits provide gravity field information primarily to the lower (near-)sectorial coefficients of the spherical harmonic spectrum, to which the GRACE inter-satellite range rates are less sensitive. 


\subsection{Satellite laser ranging (SLR)}

To stabilize the long-wavelength part of the spectrum, we added SLR observations to the combination. The observations used match the GRACE time span from April 2002 to August 2016 and feature a total of 10 satellites, including LAGEOS 1/2, Ajisai, Stella, Starlette, LARES, LARETS, Etalon $1 / 2$ and BLITS. The SLR observations were processed in weekly batches consisting of three $7 \mathrm{~d}$ arcs and one arc of variable length to complete the month, resulting in systems of normal equations $\mathbf{N}_{k}^{(s)} \hat{\boldsymbol{x}}_{k}^{(s)}=\boldsymbol{n}_{k}^{(s)}$ up to d/o 60 for each satellite $s$. To obtain the normal equations for static, trend and annual oscillation from the weekly systems of normal equations, we first perform a parameter transformation. We express the weekly potential coefficients $\boldsymbol{x}_{k}^{(s)}$ in terms of static, trend and annual oscillation as

$$
\begin{gathered}
\boldsymbol{x}_{k}^{(s)}=\boldsymbol{x}_{\text {static }}^{(s)}+\boldsymbol{x}_{\text {trend }}^{(s)}\left(t_{k}-t_{0}\right)+\boldsymbol{x}_{\mathrm{cos}}^{(s)} \cos \left(\omega\left(t_{k}-t_{0}\right)\right)+ \\
\boldsymbol{x}_{\sin }^{(s)} \sin \left(\omega\left(t_{k}-t_{0}\right)\right),
\end{gathered}
$$

or equivalently in matrix notation

$$
\begin{aligned}
\boldsymbol{x}_{k}^{(s)} & =\underbrace{\left[\begin{array}{llll}
\mathbf{I} & \mathbf{I} \cdot\left(t_{k}-t_{0}\right) & \mathbf{I} \cdot \cos \left(\omega\left(t_{k}-t_{0}\right)\right) & \mathbf{I} \cdot \sin \left(\omega\left(t_{k}-t_{0}\right)\right)
\end{array}\right]}_{:=\mathbf{F}} \\
& {\left[\begin{array}{c}
\boldsymbol{x}_{\text {static }}^{(s)} \\
\boldsymbol{x}_{\text {trend }}^{(s)} \\
\boldsymbol{x}_{\text {cos }}^{(s)} \\
\boldsymbol{x}_{\text {sin }}^{(s)}
\end{array}\right] . }
\end{aligned}
$$

Here, $\mathbf{I}$ is an identity matrix of appropriate dimension, $t_{0}$ is the reference epoch of the combined gravity field and $\omega$ is the angular frequency corresponding to an oscillation of $365.25 \mathrm{~d}$. Using this parameter substitution we can transform the weekly systems of normal equations and accumulate over whole time span,

$\mathbf{N}_{\mathrm{SLR}}^{(s)}=\sum_{k} \mathbf{F}^{T} \mathbf{N}_{k}^{(s)} \mathbf{F}, \quad \boldsymbol{n}_{\mathrm{SLR}}^{(s)}=\sum_{k} \mathbf{F}^{T} \boldsymbol{n}_{k}^{(s)}$.

After the accumulation we determined the relative weight between the individual SLR satellites $s$ by variance component estimation (VCE). Since we processed all satellites consistently, it is reasonable to assume that the formal errors are underestimated in the same fashion for all SLR targets, even though no proper stochastic model for the SLR observation was used in the processing. To determine the relative weights $w^{(s)}$ of the satellites, we do not make use of the full system of normal equations but only use the static part up to degree and order 10. In Table 2, the determined relative weights can be found. Note that these are specific to the processing applied here.

Additionally, we applied a Kaula constraint to stabilize the system of equations. The final normal equation matrix and right-hand side used in the combination procedure are then computed as the weighted sum of all satellites,

$\mathbf{N}_{\mathrm{SLR}}=\sum_{s} w^{(s)} \mathbf{N}^{(s)}, \quad \boldsymbol{n}_{\mathrm{SLR}}=\sum_{s} w^{(s)} \boldsymbol{n}^{(s)}$.
Table 2. Relative weights of SLR satellites determined through VCE.

\begin{tabular}{lrlr}
\hline Satellite & $w^{(s)}$ & Satellite & $w^{(s)}$ \\
\hline LAGEOS 1 & 41.9 & Etalon 1 & 1.0 \\
LAGEOS 2 & 38.3 & Etalon 2 & 1.6 \\
Ajisai & 3.2 & LARES & 1.1 \\
Stella & 3.7 & LARETS & 3.2 \\
Starlette & 2.8 & BLITS & 3.0 \\
\hline
\end{tabular}

\section{Combination process}

We combined the individual contributions from GOCE, GRACE, kinematic LEO orbits, SLR and constraints on the basis of normal equations using VCE. VCE is a widely used technique in geodesy for combining different observation groups (Koch and Kusche, 2002; Lemoine et al., 2013; Meyer et al., 2019). The general idea is to determine the relative weights $w_{*}$ between heterogeneous observation types within the same least-squares adjustment where the unknown parameters, in our case the gravity field, are estimated. Typically, this is an iterative procedure where initial weights are refined. The inverse of these weights, called variance factors, is the quotient of a residual square sum and the redundancy of the observation group. In the most general form this quotient is given as

$\sigma_{k}^{2}=\frac{\hat{\boldsymbol{e}}^{T} \boldsymbol{\Sigma}^{-1} \mathbf{V}_{k} \boldsymbol{\Sigma}^{-1} \hat{\boldsymbol{e}}}{\operatorname{trace}\left\{\left(\boldsymbol{\Sigma}^{-1}-\boldsymbol{\Sigma}^{-1} \mathbf{A}_{k} \overline{\mathbf{N}}^{-1} \mathbf{A}_{k}^{T} \boldsymbol{\Sigma}^{-1}\right) \mathbf{V}_{k}\right\}}$,

where $\hat{\boldsymbol{e}}$ represents post-fit residuals, $\boldsymbol{\Sigma}=\sum_{k} \sigma_{k}^{2} \mathbf{V}_{k}$ is the compound covariance matrix and $\mathbf{A}_{k}$ is the design matrix of the $k$ th observation group. The iterative nature of VCE can be seen in Eq. (8) where the compound covariance matrix computed from the variance factors of the previous iteration is necessary to compute the new values. For observation groups which are given as normal equations, so all satellite contributions and also the Kaula constraint, this simplifies to

$\sigma_{k}^{2}=\frac{\left(\boldsymbol{l}^{T} \mathbf{P} \boldsymbol{l}\right)_{k}-2 \boldsymbol{n}^{T} \hat{\boldsymbol{x}}+\hat{\boldsymbol{x}}^{T} \mathbf{N}_{k} \hat{\boldsymbol{x}}}{n-\operatorname{trace}\left\{\overline{\mathbf{N}}^{-1} \mathbf{N}_{k}\right\} \cdot \sigma_{k}^{-2}}$.

The general form presented in Eq. (8) comes into play when we determine the weights of the regionally varying constraints for the trend and annual signal (see Sect. 3.1). There we find that, for example, the variance factors for the trend constraint can be computed from

$\sigma_{k}^{2}=\frac{\hat{\boldsymbol{x}}_{\text {trend }}^{T} \boldsymbol{\Sigma}_{\Omega}^{-1} \mathbf{V}_{k} \boldsymbol{\Sigma}_{\Omega}^{-1} \hat{\boldsymbol{x}}_{\text {trend }}}{\operatorname{trace}\left\{\left[\boldsymbol{\Sigma}_{\Omega}^{-1}-\boldsymbol{\Sigma}_{\Omega}^{-1}\left(\overline{\mathbf{N}}_{\text {trend }}+\boldsymbol{\Sigma}_{\Omega}^{-1}\right)^{-1} \boldsymbol{\Sigma}_{\Omega}^{-1}\right] \mathbf{V}_{k}\right\}}$

Here, $\hat{\boldsymbol{x}}_{\text {trend }}$ represents the estimated trend parameters, and $\overline{\mathbf{N}}_{\text {trend }}$ is the accumulated system of normal equations of all satellites. The determination of the relative weights $w_{*}=\frac{1}{\sigma_{*}^{2}}$ 
is a key criterion for the overall solution quality. The GOCE, GRACE and kinematic orbit contributions feature a proper stochastic model of the observables used and therefore realistic formal errors. This is a prerequisite for a proper determination of relative weights using VCE (Meyer et al., 2019). Consequently, the weights of these contributions remain close to 1 throughout the VCE iterations. The SLR contribution used here lacks an adequate stochastic observation model, which results in formal accuracies that are too optimistic. To counteract the high weights arising from this mismodeling, the SLR system of normal equations was artificially down weighted by a factor of 10 in each iteration step. The full, accumulated system of normal equations solved in each iteration step is given by

$$
\begin{aligned}
\overline{\mathbf{N}} & =w_{\mathrm{GOCE}} \mathbf{N}_{\mathrm{GOCE}}+w_{\mathrm{GRACE}} \mathbf{N}_{\mathrm{GRACE}}+w_{\mathrm{LEO}} \mathbf{N}_{\mathrm{LEO}} \\
& +w_{\mathrm{SLR}} \mathbf{N}_{\mathrm{SLR}}+w_{\mathrm{Kaula}} \mathbf{K}+\boldsymbol{\Sigma}_{\text {trend }}^{-1}\left(\boldsymbol{w}_{\text {trend }}\right) \\
& +\boldsymbol{\Sigma}_{\text {annual }}^{-1}\left(\boldsymbol{w}_{\text {annual }}\right) \\
\overline{\boldsymbol{n}} & =w_{\mathrm{GOCE}} \boldsymbol{n}_{\mathrm{GOCE}}+w_{\mathrm{GRACE}} \boldsymbol{n}_{\mathrm{GRACE}} \\
& +w_{\mathrm{LEO}} \boldsymbol{n}_{\mathrm{LEO}}+w_{\mathrm{SLR}} \boldsymbol{n}_{\mathrm{SLR}} .
\end{aligned}
$$

It features all satellite contributions as well as constraints for certain parameters. In order to reduce the power in the higher spherical harmonic degrees and specifically the polar regions where the GOCE gradiometer observation provides little to no information, the solution is zero-constrained using a Kaula-type signal model for degrees higher than 150 . This Kaula regularization is represented by the matrix $\mathbf{K}$. Furthermore, the co-estimated trend and annual oscillation are also zero-constrained with regionally varying regularization matrix $\boldsymbol{\Sigma}_{\text {trend }}^{-1}$ and $\boldsymbol{\Sigma}_{\text {annual }}^{-1}$ respectively. The vectors $\boldsymbol{w}_{\text {trend }}$ and $\boldsymbol{w}_{\text {annual }}$ contain the weights for each modeled region (see Sect. 3.1).

The accumulation of the individual contributions in Eq. (11) assumes that the individual normal equations are of the same dimension. Since the maximum expansion degree differs between the techniques and not all contribute to the temporal variations, the systems of normal equations have to be zero-padded. The structure of the combined normal equation coefficient matrix is depicted in Fig. 1.

We estimate 211788 parameters in total with 90597 to describe the static gravity field and 121191 parameters for the co-estimated temporal variations. Another 121191 parameters representing co-seismic mass change caused by major earthquakes (see Sect. 3.3) have been pre-eliminated. The upper triangle of the (symmetric) normal equation coefficient matrix therefore requires $167 \mathrm{~GB}$ of memory. The published system of normal equations only features the unconstrained static part with all temporal variations eliminated and requires only $31 \mathrm{~GB}$.

\subsection{Regularization of co-estimated temporal variations}

In order to properly decorrelate the co-estimated temporal variations from the long-term mean field, we constrained

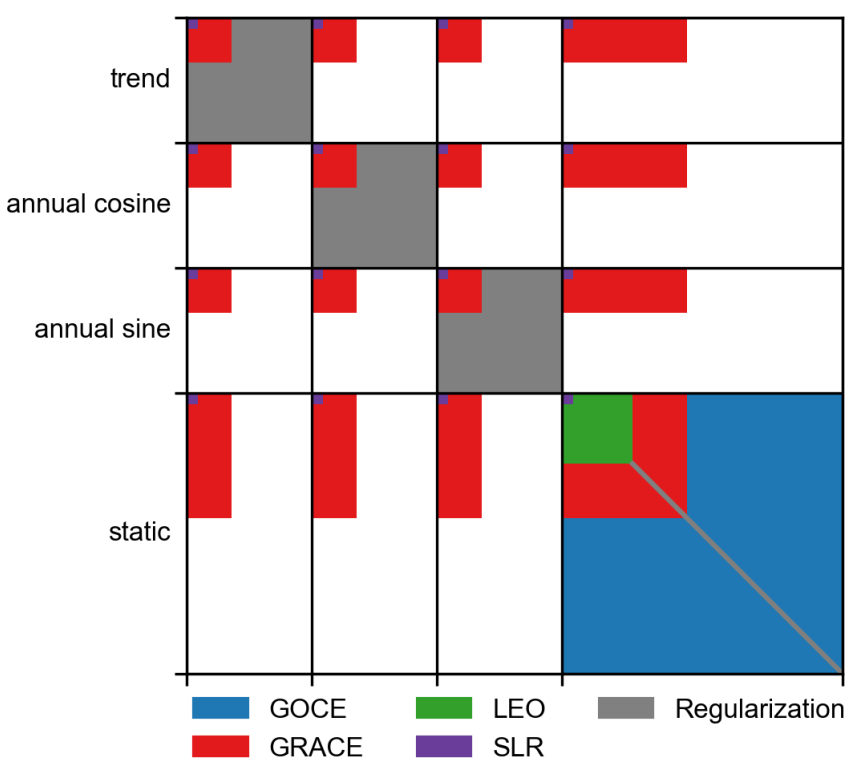

Figure 1. Structure of the combined normal equation coefficient matrix, with all contributions overlaid. The different parameter groups for trend, annual and static potential coefficients are highlighted and plotted to scale.

the corresponding parameters. While the previous solution, GOCO05s, featured a simple Kaula constraint, GOCO06s employs regionally varying prior information to account for the greatly different signal levels in individual regions. Using a globally uniform signal model, which a Kaula-type regularization provides, damps the secular signal in, for example, Greenland while overestimating the expected signal level in the ocean. To avoid this undesired behavior, but still introduce as little prior information as possible, we developed a tailored regularization strategy.

As a first step, the globe was subdivided into regions with similar temporal behavior such as the ocean, Greenland, Antarctica, the Caspian Sea and the remaining land masses. For each region $\Omega_{i}$, a signal covariance matrix was derived by applying a window matrix $\mathbf{W}_{\Omega_{i}}$ to a Kaula-type signal covariance model $\mathbf{K}$. We construct the window matrix in the space domain by making use of spherical harmonic synthesis and analysis. The general idea is to create an operator which propagates a vector of potential coefficients to source masses on a grid (Wahr et al., 1998), applying a window function to this grid and then using quadrature (Sneeuw, 1994) to transform the windowed source masses back to potential coefficients. All these operations are linear, so we can express the window matrix as a matrix product,

$\mathbf{W}_{\Omega_{i}}=\mathbf{A} \mathbf{M}_{\Omega_{i}} \mathbf{S}$.

The diagonal matrix $\mathbf{M}_{\Omega_{i}}$ is a binary window function convolved with a Gaussian kernel featuring a half width of $220 \mathrm{~km}$ (Jekeli, 1981) to mitigate ringing effects on region boundaries. 
Even though the observation contribution to the temporal variations is band-limited to degree and order 120 , as outlined in Sect. 2.2, the higher expansion degree of the signal covariance matrix does provide additional information. Specifically, the transition between regions can be modeled sharper thus enabling a better spatial separation. A similar form of this approach, which combines band-limited observation information with high-resolution prior information, can be found in Save et al. (2016). The resulting global, compound covariance matrix

$\boldsymbol{\Sigma}_{\Omega}=\sum_{i} \sigma_{i}^{2} \mathbf{W}_{\Omega_{i}} \mathbf{K} \mathbf{W}_{\Omega_{i}}^{T}=\sum_{i} \sigma_{i}^{2} \mathbf{V}_{i}$

was then used to formulate a zero constraint for trend parameters $\boldsymbol{y}$, with

$0=\mathbf{I} \boldsymbol{y}+\boldsymbol{v}, \quad \boldsymbol{v} \sim \mathcal{N}\left(\mathbf{0}, \boldsymbol{\Sigma}_{\Omega}\right)$,

where $\mathbf{I}$ is a unit matrix of appropriate dimension. The formulation of the compound covariance matrix in Eq. (14) implies that the individual regions are treated as uncorrelated. This has the side effect that $\boldsymbol{\Sigma}_{\Omega}$ will be dense, even though we use a Kaula-type signal covariance model.

For each region the unknown signal level $\sigma_{i}$ was determined through VCE during the adjustment process. This means that apart from the isotropic signal model shape, only the geographic location of the region boundaries is introduced as prior information. The same strategy was used to regularize the annual oscillation; however, the globe was subdivided into only two regions, namely continents and the ocean. Furthermore, to conserve the phase of the oscillation, a combined variance factor was estimated for both sine and cosine coefficients.

The impact of this novel approach compared to the Kaulatype regularization of the preceding GOCO satellite-only model on the estimated secular variations can be seen in Fig. 2. It is evident that the noise over the ocean is greatly reduced in GOCO06s compared to its predecessor. In regions where we have a large gradient in the signal level such as Greenland or the Antarctic Peninsula, we observe a better confinement of the signal within the land masses. This means that with the new regularization strategy, less signal leaks from land into the ocean. But there are also limitations to the employed approach. Looking at Greenland, a uniform signal level for the region is not sufficient given the dramatic mass loss at the coasts. Still, there is a clear improvement visible in the new release, GOCO06s.

\subsection{Contribution of individual components}

When dealing with combined satellite models, the contribution of each component is of particular interest. It clearly reveals the strengths and weaknesses of the different techniques in determining specific parts of the spherical harmonic spectrum. (a) GOCO05s

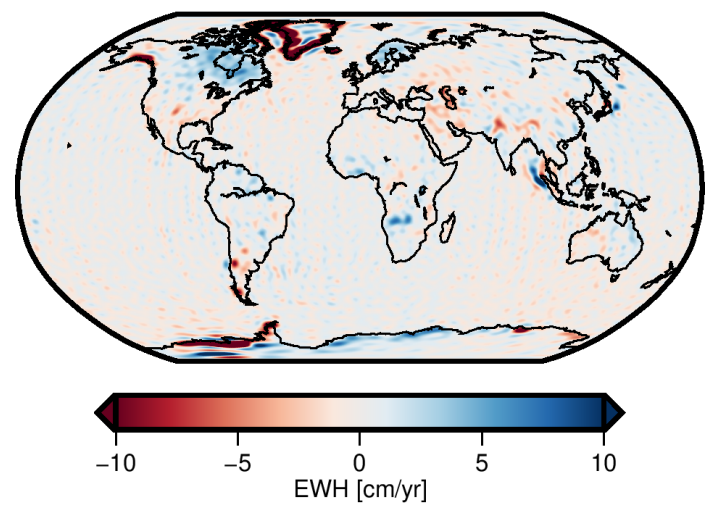

(b) GOCO06s

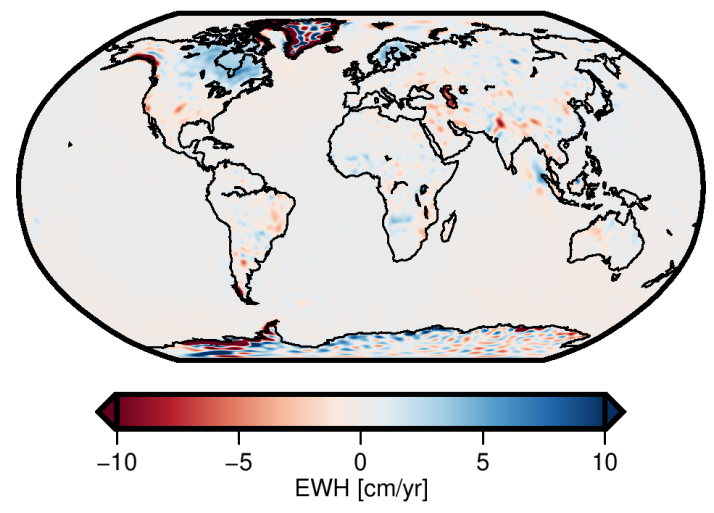

Figure 2. Co-estimated secular variation of GOCO05s (a) and GOCO06s (b) in equivalent water heights $(\mathrm{EWH})$.

We compute the contribution of each component $i \in$ \{GOCE, GRACE, LEO, SLR\} and the regularization by first assembling the contribution or redundancy matrix

$\mathbf{R}_{i}=\overline{\mathbf{N}}^{-1} \mathbf{N}_{i}$.

In Eq. (16), $\overline{\mathbf{N}}$ is the combined normal equation coefficient matrix and $\mathbf{N}_{i}$ is the normal equation coefficient matrix of the $i$ th component.

The main diagonal of $\mathbf{R}_{i}$ then gives an indication of how much each estimated parameter is informed by the respective component $i$. Since we only look at estimated potential coefficients, it is convenient to depict the contribution to each coefficient per degree and order in the coefficient triangle.

Figure 3 shows the contribution to the static gravity field of all contributing sources. We can clearly see the complementary nature of GRACE and GOCE, where the former is the primary contributor to the long-wavelength part of the spectrum up to degree 130. GRACE also constrains and compensates for the polar gap of GOCE, which can be seen in the higher contribution to the near-zonal coefficients up to degree 200. The GOCE SGG observations dominate degrees 130 to 280. Between degrees 280 and 300, where we approach a signal-to-noise ratio of 1 , the effect of regularization starts 
(a) GRACE

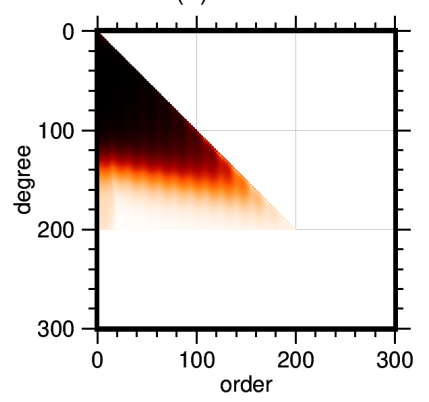

(b) GOCE SGG

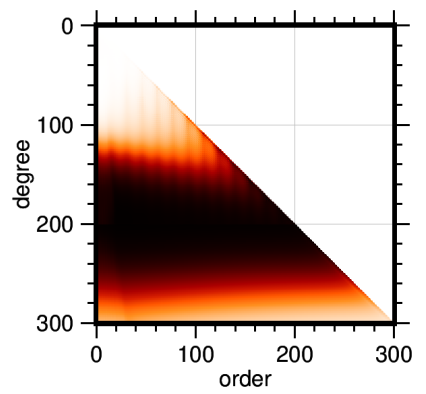

(c) regularization

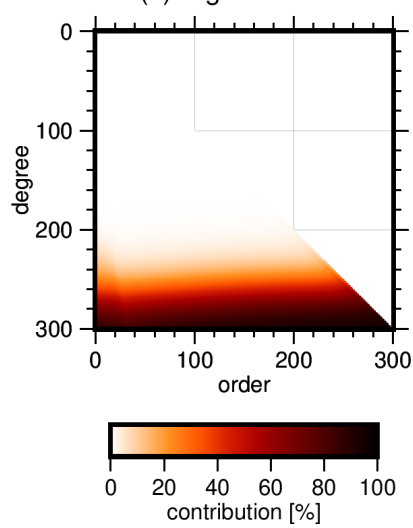

Figure 3. Individual contribution to the static part of the estimated potential coefficients for (a) GRACE, (b) GOCE SGG, (c) Kaula regularization, (d) LEO orbits and (e) SLR. Note the different axis limits for panels (d) and (e).

to play a role. LEO orbits primarily contribute to coefficients up to degree 10 and near-sectorial coefficients up to the maximum degree of the involved system of normal equations. The resonance orders of GRACE, which occur on multiples of 15 (Cheng and Ries, 2017), are clearly visible in the contribution plots. These parts of the spectrum are determined less accurately by the inter-satellite ranging data of GRACE (Seo et al., 2008) and are therefore compensated for by the other techniques (see, e.g., the higher contribution of GOCE in this order).

SLR primarily contributes to degree 2 and even zonal coefficients up to degree 12 , with a minor contribution to the (a) GRACE
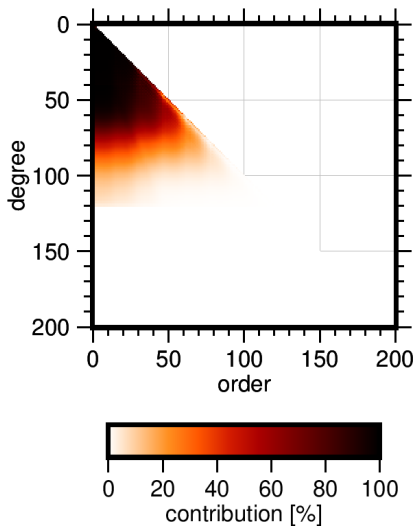

(b) SLR
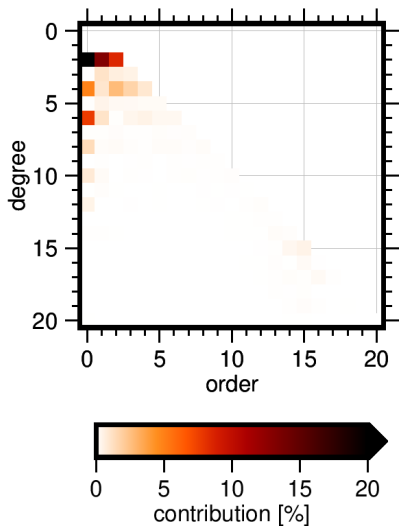

Figure 4. Contribution of (a) GRACE and (b) SLR to the estimated trend. Note the different axis limits. (a) GRACE

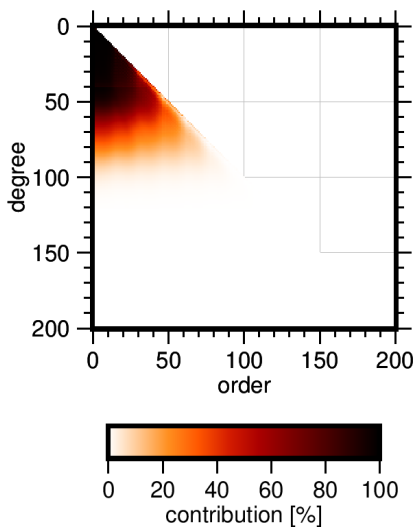

(b) SLR

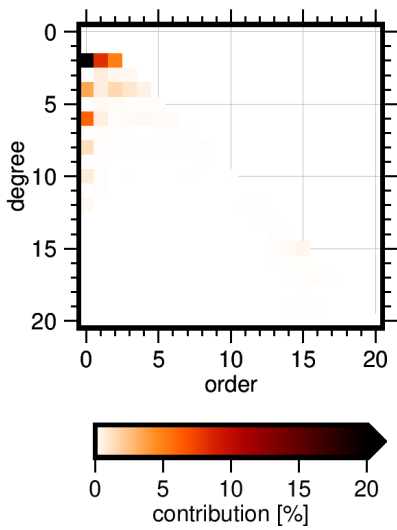

Figure 5. Contribution of (a) GRACE and (b) SLR to the estimated annual oscillation. Note the different axis limits.

near-sectorials around degree 15 . These findings are consistent with Bloßfeld et al. (2015).

We find a similar picture when looking at the contributions for the estimated trend and annual oscillation shown in Figs. 4 and 5.

\subsection{Estimation of co-seismic gravity changes}

The simple parametrization of Earth's gravity field with static, trend and annual signal basis functions cannot capture instantaneous gravity changes caused by, for example, large earthquakes. This mismodeling results in an apparent secular variation in the affected regions as the co-seismic gravity change is mapped into the trend estimate. To avoid this behavior, we estimate an additional step function in regions where co-seismic mass change is expected, thus improving the description of the temporal evolution of Earth's gravity field. The methodology is exemplified on the basis of a single earthquake dividing the whole observation time span into two intervals $i=\{1,2\}$, where interval $i=1$ refers to obser- 
vations before the event and $i=2$ to the observations captured after the event, respectively. But it can be generalized to any number of intervals in a straightforward manner. For each interval we assemble the observation equations

$\boldsymbol{l}_{i}=\mathbf{A}_{i} \boldsymbol{x}_{i}+\boldsymbol{e}_{i} \quad \boldsymbol{e}_{i} \sim \mathcal{N}\left(\mathbf{0}, \boldsymbol{\Sigma}_{i}\right)$

with $\boldsymbol{l}_{i}$ being the observation vector, $\mathbf{A}_{i}$ the design matrix, $\boldsymbol{x}_{i}$ the static gravity field parameters and $\boldsymbol{e}_{i}$ the residual vector. We then form the blocked system of observation equations for the whole observation time span

$$
\left[\begin{array}{l}
l_{1} \\
l_{2}
\end{array}\right]=\left[\begin{array}{ll}
\mathbf{A}_{1} & \\
& \mathbf{A}_{2}
\end{array}\right]\left[\begin{array}{l}
x_{1} \\
x_{2}
\end{array}\right]+\left[\begin{array}{l}
e_{1} \\
e_{2}
\end{array}\right] .
$$

The next step is to perform the parameter transformation

$$
\left[\begin{array}{l}
x_{1} \\
x_{2}
\end{array}\right]=\left[\begin{array}{ll}
\mathbf{I} & \mathbf{I} \\
& \mathbf{I}
\end{array}\right]\left[\begin{array}{l}
z \\
x
\end{array}\right]
$$

where $\mathbf{I}$ is an identity matrix of appropriate dimension, $\boldsymbol{x}$ is the static gravity field for the whole time span and $z$ is the correction for interval $i=1$. Substituting Eq. (19) into Eq. (18) yields

$$
\left[\begin{array}{l}
l_{1} \\
l_{2}
\end{array}\right]=\left[\begin{array}{ll}
\mathbf{A}_{1} & \mathbf{A}_{1} \\
& \mathbf{A}_{2}
\end{array}\right]\left[\begin{array}{l}
z \\
x
\end{array}\right]+\left[\begin{array}{l}
\boldsymbol{e}_{1} \\
\boldsymbol{e}_{2}
\end{array}\right] .
$$

Since both $\boldsymbol{x}$ and $\boldsymbol{z}$ are global representations of Earth's gravity field, the functional model in Eq. (20) would result in a loss of redundancy in regions where no co-seismic change occurred. To counteract this overparametrization, we introduce the pseudo-observations

$0=\mathbf{W} z+\boldsymbol{w} \quad \boldsymbol{w} \sim \mathcal{N}\left(\mathbf{0}, \boldsymbol{\Sigma}_{w}\right)$,

where $\mathbf{W}$ is a window matrix covering Earth's surface except for the region where a co-seismic change is expected. After combining the pseudo-observations with the transformed observation equations in Eq. (20), the resulting system of normal equations has the structure

$$
\left[\begin{array}{cc}
\mathbf{N}_{1}+\mathbf{W}^{T} \boldsymbol{\Sigma}_{w}^{-1} \mathbf{W} & \mathbf{N}_{1} \\
\mathbf{N}_{1} & \mathbf{N}_{1}+\mathbf{N}_{2}
\end{array}\right]\left[\begin{array}{l}
\hat{z} \\
\hat{x}
\end{array}\right]=\left[\begin{array}{c}
\boldsymbol{n}_{1} \\
\boldsymbol{n}_{1}+\boldsymbol{n}_{2}
\end{array}\right] .
$$

Increasing the weight of the constraint, that is, setting $\boldsymbol{\Sigma}_{w} \rightarrow$ 0 , which in practice is done by scaling with a number close to zero, then allows a signal in $\hat{z}$ only in regions within the predefined area. This retains the redundancy in points which are not affected by the earthquake, thus not influencing the estimate $\hat{\boldsymbol{x}}$ there. We applied this approach to model three major earthquakes during the GRACE life span, specifically, the 2004 Indian Ocean earthquake (Han et al., 2006), the 2010 Chile earthquake (Han et al., 2010) and the 2011 Tohoku-Oki earthquake (Panet et al., 2018). Since GRACE is the primary contributor to the estimated temporal variations at these spatial scales, the parameter transformation was considered only for the corresponding GRACE normal equations.
The estimated co-seismic mass changes can be seen in Fig. 6 . We can clearly observe that the estimated signal is spatially confined; therefore, we retain the redundancy outside of the defined area. The advantages and limitations regarding the estimation of the trend are best exemplified by comparison with the GRACE monthly solution and the previous GOCO05s release (not accounting for co-seismic changes). Figure 7 shows the estimated trends for GOCO05s and GOCO06s (including the new co-estimated step) together with the time series of monthly solutions from ITSGGrace2018 (Kvas et al., 2019a), evaluated close to the epicenter of the 2004 Indian Ocean earthquake, where we observe a large co-seismic mass change.

We can clearly observe that adding the co-estimation of co-seismic events greatly improves the accuracy of the secular variations. However, the monthly solutions show different rates before and after the event, which can obviously not be modeled by just a uniform trend over the whole observation time span. This is however a deliberate trade-off to retain redundancy in the trend estimates and simple usability of the data set.

\section{Results and evaluation}

The complete published data set of GOCO06s consists of a static gravity field solution up to degree and order 300 , an unconstrained system of normal equations of the static part for further combination, secular and annual gravity field variations up to degree and order 200, and co-seismic mass changes for three major earthquakes. All components are published in widely used data formats such as the ICGEM format for potential coefficients (Barthelmes and Förste, 2011) and the SINEX format for normal equations (IERS, 2006).

The data product of primary interest for the community certainly is the estimated static gravity field together with its uncertainty information represented by the system of normal equations. Therefore, we focus our evaluations and discussions on these components.

Figure 8 depicts degree amplitudes of differences of stateof-the-art satellite-only gravity field models and XGM2016, a gravity field model which combines GOCO05s and terrestrial data (Pail et al., 2016). This is the explanation for the small differences between XGM2016 and GOCO05s in the low degrees where the terrestrial data do not significantly contribute. Because of the GOCE orbit inclination of $96.7^{\circ}$, no data are collected directly above the poles. This polar gap has a distinct mapping to certain low-order coefficients of the gravity field (Sneeuw and van Gelderen, 1997). Consequently, these coefficients are highly correlated and less accurately determined in GOCE-only models, such as GOCE TIM6, where no other gravity field information is used. To avoid these low-order coefficients dominating the degree amplitudes and to ensure a consistent comparison, we excluded 
(a) Indian Ocean

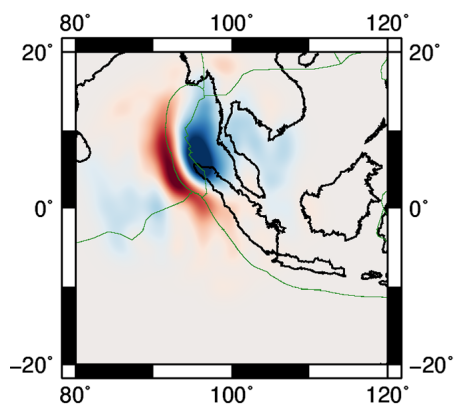

(b) Chile

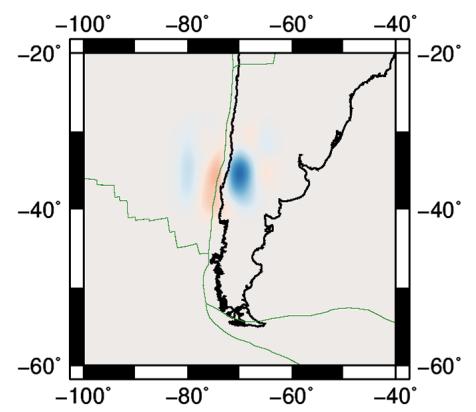

(c) Tohoku-Oki

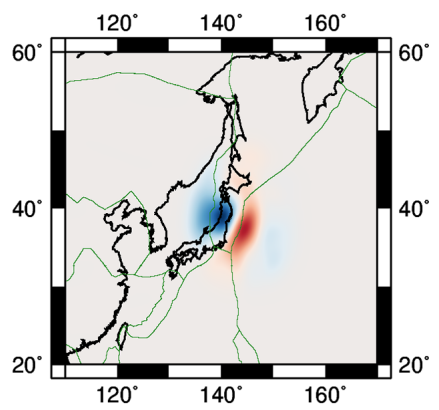

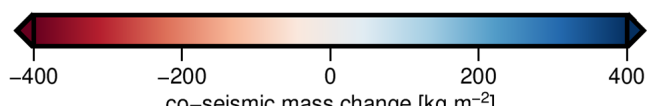

Figure 6. Estimated co-seismic mass change for all modeled earthquakes (230 km Gaussian filter applied).

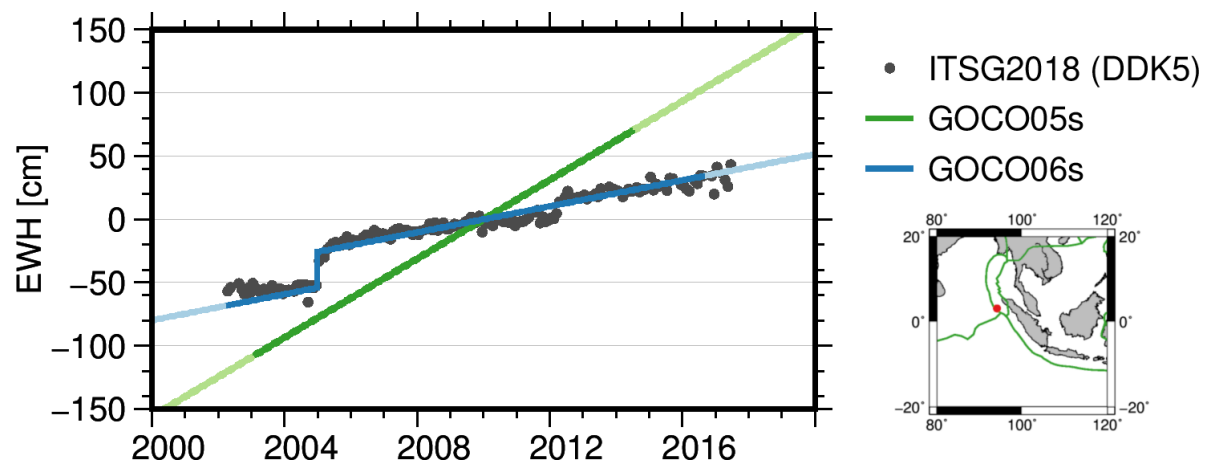

Figure 7. Comparison of estimated secular variation from GOCO05s, GOCO06s (including estimated co-seismic mass change) and filtered GRACE monthly solutions in terms of equivalent water height $(\mathrm{EWH})$. The gravity field solutions were evaluated at $94.1^{\circ} \mathrm{E}, 3.1^{\circ} \mathrm{N}$.

the coefficients corresponding to a polar cap with $8^{\circ}$ aperture angle in all models, according to the rule of thumb given in Sneeuw and van Gelderen (1997). The differences between the compared models in degrees below 60 are, on the one hand, explained by the respective reference epochs (for example, 1 January 2010 for GOCO06s and 1 September 2010 for GOCE DIR6) and, on the other hand, by the observation techniques used. GOCE TIM6 only relies on kinematic orbit data and gradiometer observations, which do not reach the superior accuracy of the GRACE inter-satellite ranging observations in this frequency band. In Fig. 8b, we can also identify differences between the solutions starting from degree 150 . Here, we can clearly distinguish between models (GOCO06s, TIM6, DIR6) based on the latest reprocessing of GOCE gradiometer data (version tag 0202) and models based on the previous release (GOCO05s, EIGEN-GRGS RL04).

Figure 9 shows the degree amplitudes of component-wise differences with respect to the combined solution of each component of GOCO06s. We excluded SLR here because the very ill posed system of normal equations can only be solved up to degree 5-6 without additional information (Cheng et al., 2011). It nicely summarizes the major contributions to the final GOCO06s solution and shows the consistency of formal and empirical errors. It further highlights the importance of stochastic modeling which enables this consistency. The deviation of the combined solution from the GOCE SGG contribution starting at degree 240 is explained by the Kaula constraint applied to the combination.

\subsection{Comparison with GNSS leveling}

Over-land geoid heights (height anomalies or geoid undulations) computed from global gravity models can be validated against independent geoid observations as they are determined by on ground GNSS leveling. By subtracting physical heights determined by spirit leveling (orthometric or normal heights) from ellipsoidal heights as they are observed with GNSS, one can compute such independent geoid heights. The challenge when comparing geoid heights derived from satellite-only gravity field models to observed geoid heights mainly is to eliminate the so-called omission error. This error, which represents the higher-resolution geoid signal not observable by satellites due to the gravitational signal attenuation at satellite altitude, causes the major part of the differ- 
(a) degrees 0 to 300
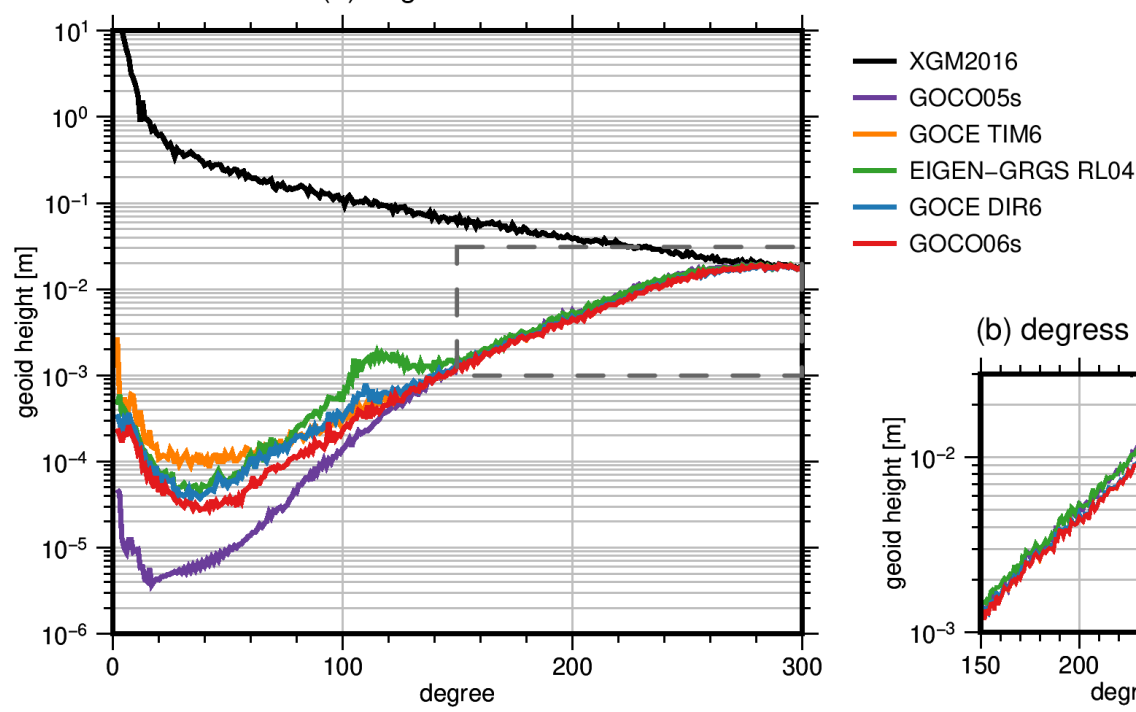

(b) degress 150 to 300

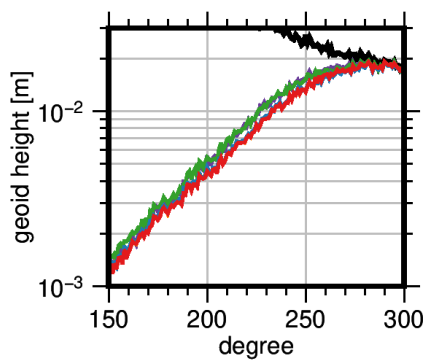

Figure 8. Difference degree amplitudes of various state-of-the-art satellite-only models compared to the combined model XGM2016 (polar cap with $8^{\circ}$ aperture angle excluded). Panel (a) shows the whole spherical harmonic spectrum covered by the models, while panel (b) only shows degrees 150 to 300 .

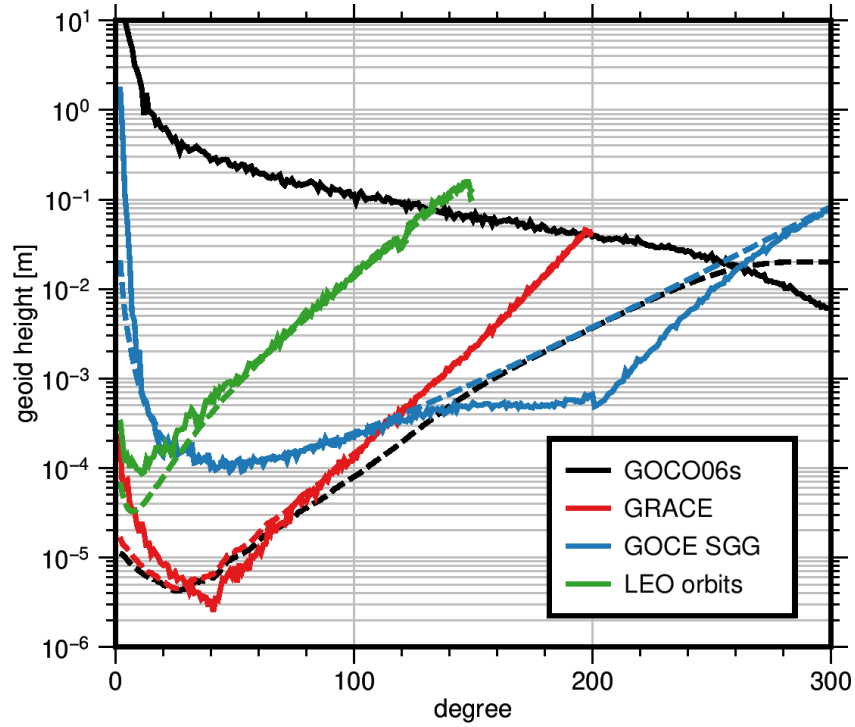

Figure 9. Difference degree amplitudes compared to GOCO06s (solid lines) and corresponding formal errors (dashed lines) of the individual GOCO06s components (polar cap with $8^{\circ}$ aperture angle excluded). SLR is not shown because no stand-alone solution can be computed due to the ill-posed adjustment problem.

ences leading to unrealistic quality estimates for the satelliteonly gravity model. Therefore, the omission error needs to be estimated from other sources and taken into account prior to computing the differences. For this purpose, high-resolution gravity field models such as EGM2008 (Pavlis et al., 2012) or XGM2019e (Zingerle et al., 2019, 2020) and an ultra- high-resolution model of the gravity signal caused by the Earth's topography such as ERTM2160 (Hirt et al., 2014) are used. The omission error computed from these models is subtracted from the observed geoid heights before they are compared to the satellite-only model geoid heights. Apart from this, a second systematic error might be present in physical heights observed by spirit leveling. Depending on the spiritleveling technique and the carefulness of the observer, errors accumulate along the leveling lines, leading to artificial tilts (or other systematics) of the physical heights with respect to the reference equipotential surface, which is defined by the height system reference point in a country. Therefore, prior to analyzing differences between observed and global-modelderived geoid heights, a correction surface for the geoid differences shall be estimated and applied. This ensures that errors due to such tilts and due to offsets of regional height systems with respect to the global geoid are eliminated beforehand. The computational procedure to compute and analyze geoid height differences between observed geoid heights and those determined from a global gravity field model is described in detail in Gruber et al. (2011) and Gruber and Willberg (2019).

For validating the GOCO06s model a number of global gravity field models and a number of GNSS-leveling data sets is applied. For gravity field models the previous satelliteonly models of the GOCO series are used (GOCO01s, GOCO02s, GOCO03s and GOCO05s). These models are characterized by combining GRACE and GOCE satellite data with an increasing number of observations and some additional satellite data (see Sect. 1). In addition, an independent SLR/GRACE/GOCE satellite-only combination 
model, namely GOCE-DIR6 (Förste et al., 2019), is used for comparisons, which to a large extent is based on the same amount of SLR, GRACE and GOCE data as GOCO06s. In order to identify the performance of pure GRACE and pure GOCE models compared to the combined GOCO06s model, the ITSG-Grace2018s (Kvas et al., 2019a) model and the GOCE-TIM6 (Brockmann et al., 2019; Brockmann et al., 2021) model are applied to the validation procedure. Finally, a model combining the GOCO06s satellite data with surface, airborne and altimetric gravity data is used in order to identify the signal content in higher degrees of the GOCO06s model. This is the XGM2019e high-resolution global gravity field model (Zingerle et al., 2019, 2020). GNSS-leveling data are available from many sources for many areas in the world. Typically, these data sets show different quality levels, which strongly depend on the instruments, the measurement procedure and the observer carefulness. In general, the results for most of the comparisons show similar behavior but at different levels of accuracy. We have selected representative data sets from different continents and of different quality levels and validated the model-derived geoid heights against these data sets. Here we show the results for Brazil, Germany, Japan and the United States (see Acknowledgements).

Figure 10 shows the results for the validation of the global models against the independently observed geoid heights at GNSS-leveling points for the four selected countries. Before drawing any conclusion from the results, the figure shall be explained shortly. Each tested model was truncated at steps of degree 10 of the spherical harmonic series starting from degree and order 10 until 300. For each area the model geoid heights were computed up to the degree and order given on the $x$ axis, and differences compared to the observed geoid heights were calculated. The omission error was computed separately from the EGM2008 and ERTM2160 models (see above) starting from the truncation degree to highest possible resolution and subtracted from the geoid differences. Finally, a planar correction surface was calculated for each area for the geoid differences and subtracted. From the remaining differences the root-mean-square (rms) values shown on the $y$ axis were computed. In general, the lowest level of the rms values is a good indicator of the quality of the GNSSleveling-derived geoid heights as one can assume that the global satellite-only models perform similarly over the whole globe.

Regarding this it becomes obvious that the German data set seems to be the best ground data set, while the Brazilian data set on average suffers from some inaccuracies, which are due to the size of the country and other geodetic infrastructure weaknesses. For Japan and the United States the rms of differences is at a level of 7.5 and $9.5 \mathrm{~cm}$ respectively. The general shape of the curves is completely different for Brazil and the other data sets under investigation. The reason behind this is that the more information from the EGM2008 model (without GOCE data) is used for computing the omis- sion error the worse the result of the differences is. This indicates that GOCE data can significantly improve the overall performance of the global gravity field models in case no high-quality ground data are available. In the other areas we consider here high-quality ground data were used in EGM2008, and therefore it performs very well when most of the signal is computed from this model (i.e., for low truncation degrees). Looking to the different satellite-only solutions one can identify the limit of a pure GRACE solution (ITSG-Grace2018s) as the rms of the differences starts to increase at lower degrees than for the other models. Including GOCE (and more GRACE) data significantly improves the higher-resolution terms of the satellite-only models as it can be seen from the series from GOCO01s to GOCO06s, where the higher release number means more satellite information included. When comparing the satellite-only models to the combined XGM2019e model, the degree where they start to diverge somehow represents the maximum signal content of the satellite-only models, or in other words up to what degree and order such a model contains the full gravity field signal. Depending on the area, we can identify that around degree 200 the models start to diverge. For Germany, where we probably have the best ground data set, the satellite contribution is superior and may be up to degree 180 . Regarding the GOCO06s model we can state from these comparisons that it is a state-of-the-art satellite-only model and that it performs best together with the GOCE-DIR6 and GOCE-TIM6 models, which on the higher end of the spectrum are all based on the same complete GOCE data set.

\subsection{Orbit residuals}

To evaluate the long-wavelength part of GOCO06s, we analyze orbit residuals between integrated dynamic orbits and GPS-derived kinematic orbits of four LEO satellites of various altitudes and inclinations. The missions used with corresponding altitude and inclination are GOCE $(\approx 250 \mathrm{~km}$, $96.7^{\circ}$ ), TerraSAR-X (Buckreuss et al., 2003, $\approx 515 \mathrm{~km}$, $98^{\circ}$ ), Jason-2 (Neeck and Vaze, $2008, \approx 1330 \mathrm{~km}, 66^{\circ}$ ) and GRACE-B $\left(\approx 450 \mathrm{~km}, 89^{\circ}\right)$. We realize that this is not a fully independent evaluation since GOCO06s contains kinematic orbit data from the LEO satellites considered here. However, since the overall contribution of the GPS positions to the gravity field is very low (see Sect. 3.2), we argue that this approach still gives valid conclusions. Furthermore, we used the kinematic GOCE and GRACE orbits of the Astronomical Institute at Bern University (Bock et al., 2014; Meyer et al., 2016) and not the in-house positions used in the gravity field recovery process.

First, a dynamic orbit for each satellite is integrated based on a fixed set of geophysical models, where only the static gravity field is substituted.

The models used can be found in Table 3. We included trend and annual gravity field variations from GRACE to 
(a) Brazil (1180 points)

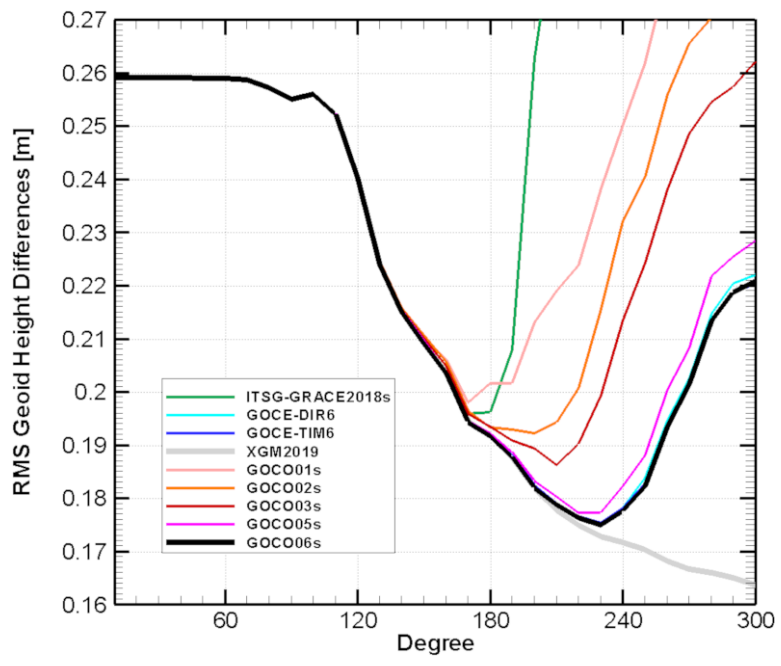

(c) Japan (837 points)

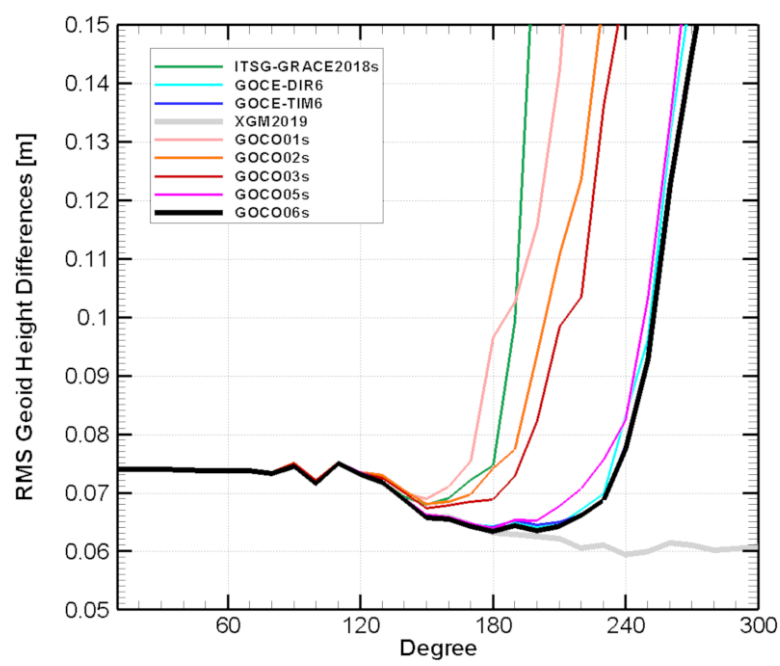

(b) Germany (470 points)

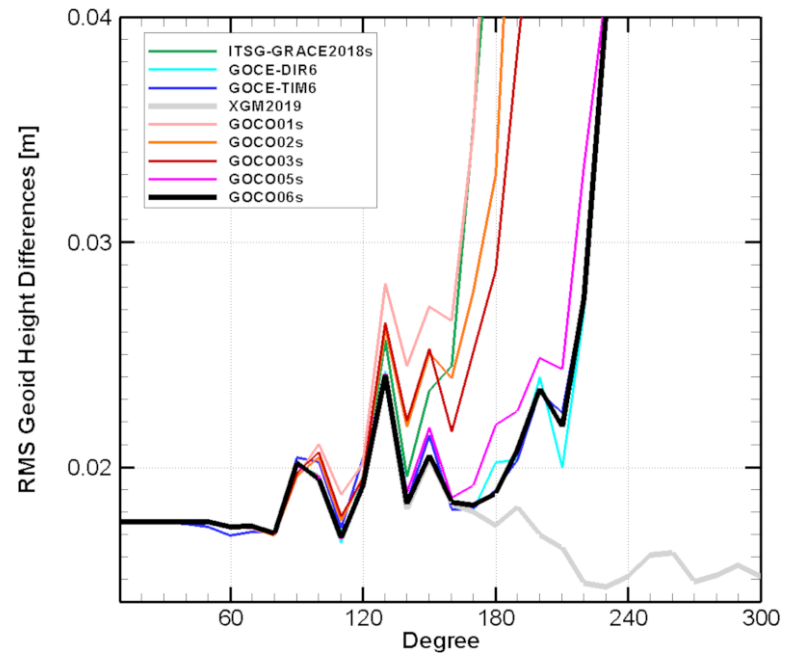

(d) USA (24872 points)

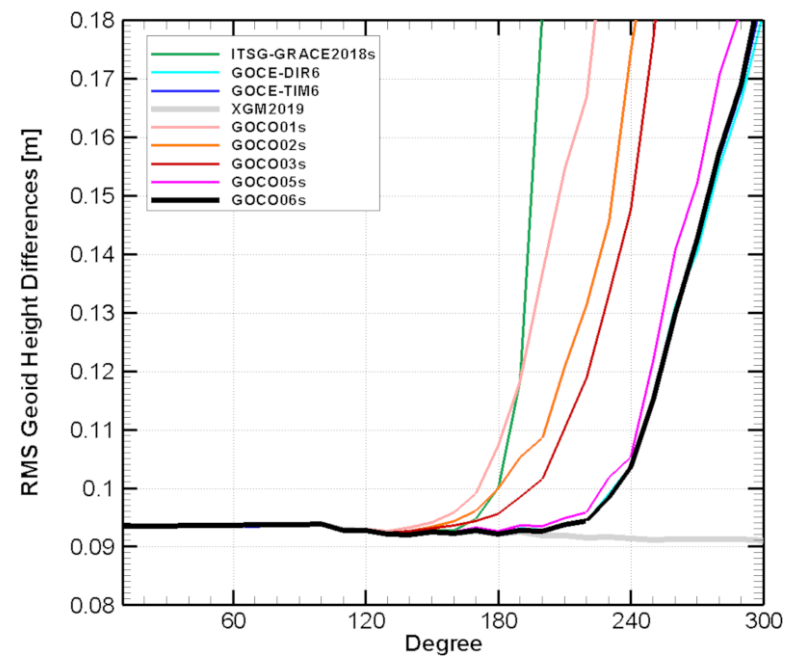

Figure 10. Root mean square of geoid height differences between global gravity models and independently observed geoid heights from GNSS leveling. Global models are truncated with steps of $10^{\circ}$ starting from degree and order 10 to degree and order 300 . The omission error is computed from the degree of truncation to degree and order 2190 from EGM2008 and from the ERTM2160 topographic gravity field model for degrees above 2160 .

make sure all compared gravity fields relate to the same reference epoch.

Since satellites are not only affected by gravitational forces, but also non-conservative forces such as atmospheric drag, solar radiation pressure and Earth radiation pressure, both GOCE and GRACE are equipped with accelerometers which measure the impact of these forces. The other satellites (Jason-2, TerraSAR-X) do not feature such an instrument; therefore, we make use of models to compute the effect. Specifically, we model the impact of atmospheric drag (Bowman et al., 2008), Earth's albedo (Knocke et al., 1988) and solar radiation pressure (Lemoine et al., 2013). Even though the quality of accelerometer measurements is gener- ally superior to the model output, sensor-specific errors such as bias and scale need to be considered. Consequently we model and estimate both bias and scale as well as empirical parameters for both accelerometers and model output to reduce the potential impact of mismodeling and sensor errors on our evaluation. The values of these calibration parameters are estimated together with the initial state when the dynamic orbit is fitted to the kinematic satellite positions. One constant bias for each axis and a single full-scale matrix (Klinger and Mayer-Gürr, 2016) is estimated per each $1 \mathrm{~d}$ arc for all satellites. For Jason- 2 and TerraSAR-X we additionally estimate a once-per-revolution bias to further reduce the impact of non-conservative forces. The metric we are us- 
Table 3. Background models used in the dynamic orbit integration.

\begin{tabular}{lll}
\hline Force & Model & Maximum degree \\
\hline $\begin{array}{l}\text { Earth's static gravity field } \\
\text { Annual/secular variations } \\
\quad \text { of Earth's gravity field }\end{array}$ & static part of evaluated models & 200 \\
Non-tidal ocean/atmosphere variation & AOD1B RL06 & 96 \\
Ocean tides & FES2014b & 180 \\
Astronomical tides & IERS2010, JPL DE421 & 180 \\
Solid Earth tides & IERS2010 & N/A \\
Atmospheric tides & AOD1B RL06 & 4 \\
Pole tides & IERS2010 (linear mean pole) & 180 \\
Ocean pole tides & Desai (2002, linear mean pole) & $c_{21}, s_{21}$ \\
Relativistic corrections & IERS2010 & 220 \\
Non-conservative forces & measured if available, otherwise & - \\
\multicolumn{2}{l}{ JB2008 (drag), Knocke et al. (1988)/CERES (albedo), } \\
\end{tabular}

ing for the evaluation is the root mean square (rms) of the orbit differences between the integrated dynamic orbit and the purely GPS derived kinematic orbit positions. Epochs where the difference exceeds $15 \mathrm{~cm}$ are treated as outliers and subsequently removed. We randomly selected 4 months over the GOCE measurement time span (November 2009, March 2010, October 2011 and March 2012).

We compare GOCO06s with its predecessor GOCO05s and other recent static gravity field models (see Fig. 8) available on ICGEM (Ince et al., 2019). The results are summarized in Table 4.

From the computed rms values we can conclude that the most recent combination models (GOCO06s and DIR6) perform nearly equally well, with GOCO06s having a slight edge. Furthermore, we can see that there is a quality jump from the previous release, GOCO05s. The GOCE-only model TIM6 performs the worst for all satellites, which highlights the importance of GRACE for stabilizing the long to medium wavelengths and the polar gap. The overall larger rms values for TerraSAR-X and Jason- 2 reflect the challenges in modeling non-conservative forces for these satellites. Combined with the higher altitude, the contrast between the individual static gravity field solutions becomes very small. Still, we observe the same tendencies as for GOCE and GRACE.

Next to the validation of static gravity fields, orbit residuals are also very useful in evaluating the temporal constituents of gravity field solutions. We gauge the quality of the co-estimated temporal constituents of GOCO06s by integrating dynamic orbit arcs for GRACE Follow-On 1 (GRACE-C). We compare GOCO06s to EIGEN-GRGS RL04, a recent gravity field model which also features a time-variable part; the previous solution, GOCO05s; and a GRACE-FO monthly solution. Instead of the trend and annual variation estimated from CSR RL06, we use the temporal constituents of the gravity fields to be compared. Both
GOCO06s and GOCO05s provide secular and annual variations, while EIGEN-GRGS RL04 has secular, annual and semi-annual variations estimated for shorter intervals. We perform the evaluation for January 2020, which is well beyond the GRACE measurement time span. This choice is deliberate to assess the extrapolation capabilities of the compared gravity fields. The computed rms values can be found in Table 5.

We can see that GOCO06s outperforms both its predecessor and EIGEN-GRGS RL04 while, unsurprisingly, the GRACE-FO monthly solution performs best.

\section{Data availability}

The primary model data consisting of potential coefficients representing Earth's static gravity field, together with secular and annual variations, are available on ICGEM (Ince et al., 2019). This data set is identified with the following DOI: https://doi.org/10.5880/ICGEM.2019.002 (Kvas et al., 2019b) .

Supplementary material consisting of the full variancecovariance matrix of the static potential coefficients and estimated co-seismic mass changes is available at https://ifg. tugraz.at/GOCO (last access: 11 June 2020).

\section{Conclusions}

The satellite-only gravity field model GOCO06s provides a consistent combination of spaceborne gravity observations from a variety of satellite missions and measurement techniques. Each component of the solution was processed using state-of-the-art methodology which results in a clear increase in the solution quality compared to the preceding GOCO solutions and the individual input models. All contributing data sources were combined on the basis of full normal equations, with the individual weights being determined by VCE. The 
Table 4. Root mean square of differences between integrated dynamic and GPS-derived kinematic orbits in centimeters for four selected months during the GOCE measurement time span for satellites of different altitude and inclination.

\begin{tabular}{lrrrr}
\hline & GOCO05s & GOCO06s & GOCE TIM6 & GOCE DIR6 \\
\hline GOCE & 2.39 & 2.36 & 3.54 & 2.39 \\
TerraSAR-X & 5.66 & 5.65 & 5.73 & 5.67 \\
Jason-2 & 3.89 & 3.88 & 4.00 & 3.88 \\
GRACE-B & 2.41 & 2.24 & 5.08 & 2.25 \\
\hline
\end{tabular}

Table 5. Root mean square of differences between integrated dynamic orbit and GPS-derived kinematic positions for GRACE-C in January 2020 in centimeters.

\begin{tabular}{rrrrc}
\hline & EIGEN-GRGS RL04 & GOCO06s & GOCO05s & ITSG-Grace op \\
\hline GRACE-C & 3.06 & 2.44 & 2.60 & 2.32 \\
\hline
\end{tabular}

long to medium spatial wavelengths covered by GOCO06s are mainly determined by GRACE due to the high sensitivity of the inter-satellite ranging observation to this frequency band. SLR primarily contributes to degree 2, while the kinematic LEO orbits mainly contribute to the sectorial coefficients up to degree and order 150. Finally, the medium to short wavelengths of the solution, starting from degree 120 , are dominated by the GOCE gradiometer observations. To reduce the energy in the higher spherical harmonic degrees, a Kaula-type regularization was applied from degree 151 to 300. The complementary nature of the data that were used mitigates weaknesses of the individual observation types, thus providing the highest accuracy throughout the spatial frequency band covered by the solution.

Since an appropriate stochastic observation model is used during processing, GOCO06s exhibits realistic formal errors, which alleviates further combination with additional, for example, terrestrial gravity field observations (Pail et al., 2016, 2018). This extremely useful information is provided to the community in the form of the full system of unconstrained normal equations. All data products are published in well established file formats such as the ICGEM format for potential coefficients (Barthelmes and Förste, 2011) and the SINEX format (IERS, 2006) for systems of normal equations.

Author contributions. AK computed the GRACE and LEO normal equations, developed and implemented the regularization strategies for the temporal constituents and earthquakes, performed the combination of all individual data contributions, performed the orbit validation, and partially wrote the manuscript. JMB computed the GOCE SGG system of normal equations and partially wrote the manuscript. TS and WDS contributed to the GOCE processing. SK computed and provided the systems of normal equations for all SLR satellites. TG performed the model validation with in situ GNSS-leveling data. UM provided the kinematic orbits of GRACE and GOCE used in the validation. TMG, AJ, WDS and RP acted as scientific advisors. All authors commented on the draft of the manuscript and on the discussion of the results.

Competing interests. The authors declare that they have no conflict of interest.

Acknowledgements. Jan Martin Brockmann and Wolf-Dieter Schuh gratefully acknowledge the Gauss Centre for Supercomputing e.V. (http://www.gauss-centre.eu, last access: 20 January 2021) for funding this study by providing computing time through the John von Neumann Institute for Computing (NIC) on the GCS supercomputer JUWELS at the Jülich Supercomputing Centre (JSC).

Precise orbit determination of SLR satellites was accomplished with the software package GEODYN, kindly provided by the NASA Goddard Space Flight Center.

GNSS-leveling data sets applied in this study have been kindly provided by the Brazilian Institute of Geography and Statistics IBGE, 2019 (Brazil); by the GeoBasis-DE/Geobasis NRW, 2018 (Germany); by the Japanese Geographical Survey Institute, 2003 (Japan); and by the National Geodetic Survey, 2012 (USA). The authors are grateful to the institutions who made available the GNSSleveling data as they provide a unique reference for validating global gravity field models.

The authors gratefully acknowledge the ISDC at the German Research Centre for Geosciences for providing Champ, TerraSAR$\mathrm{X}$ and TanDEM-X data; the European Space Agency for providing GOCE and SWARM data; Aviso for providing Jason data; and the International Laser Ranging Service for providing satellite laser ranging measurements.

Financial support. This research has been supported by the ESA GOCE HPF (grant no. 18308/04/NL/MM).

Review statement. This paper was edited by Christian Voigt and reviewed by two anonymous referees. 


\section{References}

Abrehdary, M., Sjoberg, L. E., Bagherbandi, M., and Sampietro, D.: Towards the Moho Depth and Moho Density Contrast along with Their Uncertainties from Seismic and Satellite Gravity Observations, J. Appl. Geod., 11, 231-247, https://doi.org/10.1515/jag2017-0019, 2017.

Barthelmes, F. and Förste, C.: The ICGEM-format, Tech. rep., GFZ Potsdam, Department 1 Geodesy and Remote Sensing, available at: http://icgem.gfz-potsdam.de/ICGEM-Format-2011.pdf, last access: 20 January 2021), 2011.

Battrick, B. (Ed.): The Four Candidate Earth Explorer Core Missions - Gravity Field and Steady-State Ocean Circulation, vol. 1233 of ESA SP, ESA Publications Division, Noordwijk, Netherlands, 1999.

Beutler, G., Jäggi, A., Mervart, L., and Meyer, U.: The Celestial Mechanics Approach: Theoretical Foundations, J. Geodesy, 84, 605-624, https://doi.org/10.1007/s00190-010-0401-7, 2010.

Bezděk, A., Sebera, J., Teixeira da Encarnação, J., and Klokočník, J.: Time-Variable Gravity Fields Derived from GPS Tracking of Swarm, Geophys. J. Int., 205, 1665-1669, https://doi.org/10.1093/gji/ggw094, 2016.

Bingham, R. J., Haines, K., and Lea, D. J.: How Well Can We Measure the Ocean's Mean Dynamic Topography from Space?, J. Geophys. Res.-Oceans, 119, 3336-3356, https://doi.org/10.1002/2013JC009354, 2014.

Bloßfeld, M., Müller, H., Gerstl, M., Štefka, V., Bouman, J., Göttl, F., and Horwath, M.: Second-degree Stokes coefficients from multi-satellite SLR, J. Geodesy, 89, 857-871, https://doi.org/10.1007/s00190-015-0819-z, 2015.

Bloßfeld, M., Rudenko, S., Kehm, A., Panafidina, N., Müller, H., Angermann, D., Hugentobler, U., and Seitz, M.: Consistent Estimation of Geodetic Parameters from SLR Satellite Constellation Measurements, J. Geodesy, 92, 1003-1021, https://doi.org/10.1007/s00190-018-1166-7, 2018.

Bock, H., Jäggi, A., Beutler, G., and Meyer, U.: GOCE: precise orbit determination for the entire mission, J. Geodesy, 88, 1047-1060, https://doi.org/10.1007/s00190-014-0742-8, 2014.

Bowman, B. R., Tobiska, W. K., Marcos, F. A., Huang, C. Y., Lin, C. S., and Burke, W. J.: A new empirical thermospheric density model JB2008 using new solar and geomagnetic indices, in: AIAA/AAS Astrodynamics Specialist Conference and Exhibit, American Institute of Aeronautics and Astronautics, https://doi.org/10.2514/6.2008-6438, 2008.

Brockmann, J. M., Zehentner, N., Höck, E., Pail, R., Loth, I., Mayer-Gürr, T., and Schuh, W.-D.: EGM_TIM_RL05: An Independent Geoid with Centimeter Accuracy Purely Based on the GOCE Mission, Geophys. Res. Lett., 41, 8089-8099, https://doi.org/10.1002/2014GL061904, 2014.

Brockmann, J. M., Schubert, T., Mayer-Gürr, T., and Schuh, W.-D.: The Earth's Gravity Field as Seen by the GOCE Satellite - an Improved Sixth Release Derived with the Time-Wise Approach (GO_CONS_GCF_2_TIM_R6), ICGEM, https://doi.org/10.5880/icgem.2019.003, 2019.

Brockmann, J. M., Schubert, T., and Schuh, W.-D.: An Improved Model of the Earth's Static Gravity Field Solely Derived from Reprocessed GOCE Data, Surv. Geophys. https://doi.org/10.1007/s10712-020- 09626-0, online first, 2021.
Bruinsma, S., Lemoine, J.-M., Biancale, R., and Valès, N.: CNES/GRGS 10-day gravity field models (release 2) and their evaluation, Adv. Space Res., 45, 587-601, https://doi.org/10.1016/j.asr.2009.10.012, 2010.

Bruinsma, S. L., Förste, C., Abrikosov, O., Marty, J.-C., Rio, M.-H., Mulet, S., and Bonvalot, S.: The New ESA Satellite-Only Gravity Field Model via the Direct Approach, Geophys. Res. Lett., 40, 3607-3612, https://doi.org/10.1002/grl.50716, 2013.

Bruinsma, S. L., Förste, C., Abrikosov, O., Lemoine, J.-M., Marty, J.-C., Mulet, S., Rio, M.-H., and Bonvalot, S.: ESA's Satellite-Only Gravity Field Model via the Direct Approach Based on All GOCE Data, Geophys. Res. Lett., 41, GL062045, https://doi.org/10.1002/2014GL062045, 2014.

Buckreuss, S., Balzer, W., Muhlbauer, P., Werninghaus, R., and Pitz, W.: The terraSAR-X satellite project, in: IGARSS 2003, 2003 IEEE International Geoscience and Remote Sensing Symposium, Proceedings (IEEE Cat. No.03CH37477), 5, 3096-3098, 2003.

Carrere, L., Lyard, F., Cancet, M., and Guillot, A.: FES 2014, a New Tidal Model on the Global Ocean with Enhanced Accuracy in Shallow Seas and in the Arctic Region, in: EGU General Assembly, 17, p. 5481, Vienna, Austria, available at: http://adsabs.harvard.edu/abs/2015EGUGA..17.5481C (last access: 20 January 2021), 2015.

Chen, Q., Shen, Y., Francis, O., Chen, W., Zhang, X., and Hsu, H.: Tongji-Grace02s and Tongji-Grace02k: High-Precision Static GRACE-Only Global Earth's Gravity Field Models Derived by Refined Data Processing Strategies, J. Geophys. Res.-Sol. Ea., 123, 6111-6137, https://doi.org/10.1029/2018JB015641, 2018.

Chen, W., Braitenberg, C., and Serpelloni, E.: Interference of Tectonic Signals in Subsurface Hydrologic Monitoring through Gravity and GPS Due to Mountain Building, Global Planet. Change, 167, 148-159, https://doi.org/10.1016/j.gloplacha.2018.05.003, 2018.

Cheng, M. and Ries, J.: The unexpected signal in GRACE estimates of $C_{20}$, J. Geodesy, 91, 897-914, https://doi.org/10.1007/s00190-016-0995-5, 2017.

Cheng, M., Ries, J. C., and Tapley, B. D.: Variations of the Earth's figure axis from satellite laser ranging and GRACE, J. Geophys. Res.-Sol. Ea., 116, B01409, https://doi.org/10.1029/2010JB000850, 2011.

Dahle, C., Murböck, M., Flechtner, F., Dobslaw, H., Michalak, G., Neumayer, K., Abrykosov, O., Reinhold, A., König, R., Sulzbach, R., and Förste, C.: The GFZ GRACE RL06 Monthly Gravity Field Time Series: Processing Details and Quality Assessment, Remote Sensing, 11, 2116, https://doi.org/10.3390/rs11182116, 2019.

Desai, S. D.: Observing the Pole Tide with Satellite Altimetry, J. Geophys. Res.-Oceans, 107, 7-1-7-13, https://doi.org/10.1029/2001JC001224, 2002.

Dobslaw, H., Bergmann-Wolf, I., Dill, R., Poropat, L., Thomas, M., Dahle, C., Esselborn, S., König, R., and Flechtner, F.: A New High-Resolution Model of Non-Tidal Atmosphere and Ocean Mass Variability for de-Aliasing of Satellite Gravity Observations: AOD1B RL06, Geophys. J. Int., 211, 263-269, https://doi.org/10.1093/gji/ggx302, 2017.

Ebbing, J., Haas, P., Ferraccioli, F., Pappa, F., Szwillus, W., and Bouman, J.: Earth Tectonics as Seen by GOCE - En- 
hanced Satellite Gravity Gradient Imaging, Sci. Rep., 8, 16356, https://doi.org/10.1038/s41598-018-34733-9, 2018.

Ellmer, M.: Contributions to GRACE Gravity Field Recovery: Improvements in Dynamic Orbit Integration Stochastic Modelling of the Antenna Offset Correction, and Co-Estimation of Satellite Orientations, $\mathrm{PhD}$ thesis, Graz University of Technology (90000), https://doi.org/10.3217/978-3-85125-646-8, 2018.

Farahani, H. H., Ditmar, P., Klees, R., Liu, X., Zhao, Q., and Guo, J.: The Static Gravity Field Model DGM-1S from GRACE and GOCE Data: Computation, Validation and an Analysis of GOCE Mission's Added Value, J. Geodesy, 87, 843-867, https://doi.org/10.1007/s00190-013-0650-3, 2013.

Farrell, S. L., McAdoo, D. C., Laxon, S. W., Zwally, H. J., Yi, D., Ridout, A., and Giles, K.: Mean Dynamic Topography of the Arctic Ocean, Geophys. Res. Lett., 39, L01601, https://doi.org/10.1029/2011GL050052, 2012.

Floberghagen, R., Fehringer, M., Lamarre, D., Muzi, D., Frommknecht, B., Steiger, C., Piñeiro, J., and da Costa, A.: Mission design, operation and exploitation of the gravity field and steady-state ocean circulation explorer mission, J. Geodesy, 85, 749-758, https://doi.org/10.1007/s00190-011-0498-3, 2011.

Folkner, W. M., Williams, J. G., and Boggs, D. H.: The Planetary and Lunar Ephemeris DE 421, Tech. Rep. 42-178, Jet Propulsion Laborator, Pasadena, California, available at: http://adsabs. harvard.edu/abs/2009IPNPR.178C...1F (last access: 20 January 2021), 2009.

Förste, C., Bruinsma, S., Abrikosov, O., Rudenko, S., Lemoine, J.M., Marty, J.-C., Neumayer, K. H., and Biancale, R.: EIGEN6S4 A Time-Variable Satellite-Only Gravity Field Model to d/o 300 Based on LAGEOS, GRACE and GOCE Data from the Collaboration of GFZ Potsdam and GRGS Toulouse, ICGEM, https://doi.org/10.5880/icgem.2016.008, 2016.

Förste, C., Abrykosov, O., Bruinsma, S., Dahle, C., König, R., and Lemoine, J.-M.: ESA's Release 6 GOCE Gravity Field Model by Means of the Direct Approach Based on Improved Filtering of the Reprocessed Gradients of the Entire Mission (GO_CONS_GCF_2_DIR_R6), ICGEM, https://doi.org/10.5880/ICGEM.2019.004, 2019.

Gerlach, C. and Rummel, R.: Global Height System Unification with GOCE: A Simulation Study on the Indirect Bias Term in the GBVP Approach, J. Geodesy, 87, 57-67, https://doi.org/10.1007/s00190-012-0579-y, 2013.

GRACE: RACE_L1B_GRAV_JPL_RL03, Ver. 3, PO.DAAC, CA, USA, Dataset https://doi.org/10.5067/GRJPL-L1B03, 2018.

Gruber, T. and Willberg, M.: Signal and Error Assessment of GOCE-Based High Resolution Gravity Field Models, Journal of Geodetic Science, 9, 71-86, https://doi.org/10.1515/jogs-20190008, 2019.

Gruber, T., Visser, P. N. a. M., Ackermann, C., and Hosse, M.: Validation of GOCE Gravity Field Models by Means of Orbit Residuals and Geoid Comparisons, J. Geodesy, 85, 845-860, https://doi.org/10.1007/s00190-011-0486-7, 2011.

Han, S.-C., Shum, C. K., Bevis, M., Ji, C., and Kuo, C.-Y.: Crustal Dilatation Observed by GRACE After the 2004 Sumatra-Andaman Earthquake, Science, 313, 658-662, https://doi.org/10.1126/science.1128661, 2006.

Han, S.-C., Sauber, J., and Luthcke, S.: Regional gravity decrease after the 2010 Maule (Chile) earthquake indicates large- scale mass redistribution, Geophys. Res. Lett., 37, L23307, https://doi.org/10.1029/2010GL045449, 2010.

Hirt, C., Kuhn, M., Claessens, S., Pail, R., Seitz, K., and Gruber, T.: Study of the Earth's Short-Scale Gravity Field Using the ERTM2160 Gravity Model, Comput. Geosci., 73, 71-80, https://doi.org/10.1016/j.cageo.2014.09.001, 2014.

Huang, J. and Véronneau, M.: Canadian Gravimetric Geoid Model 2010, J. Geodesy, 87, 771-790, https://doi.org/10.1007/s00190013-0645-0, 2013.

IERS, I. E. R. S.: SINEX - Solution (Software/technique) INdependent EXchange Format Version 2.02, Tech. rep., International Earth Rotation Service (IERS), available at: https://www.iers.org/IERS/EN/Organization/ AnalysisCoordinator/SinexFormat/sinex.html (last access: 20 January 2021), 2006.

Ince, E. S., Barthelmes, F., Reißland, S., Elger, K., Förste, C., Flechtner, F., and Schuh, H.: ICGEM - 15 years of successful collection and distribution of global gravitational models, associated services, and future plans, Earth Syst. Sci. Data, 11, 647674, https://doi.org/10.5194/essd-11-647-2019, 2019.

Jekeli, C.: Alternative methods to smooth the Earth's gravity field, Tech. Rep. 327, Department of Geodetic Science and Surveying, Ohio State Univ., Columbus, OH, 1981.

Johannessen, J. A., Balmino, G., Provost, C. L., Rummel, R., Sabadini, R., Sünkel, H., Tscherning, C. C., Visser, P., Woodworth, P., Hughes, C., Legrand, P., Sneeuw, N., Perosanz, F., Aguirre-Martinez, M., Rebhan, H., and Drinkwater, M.: The European Gravity Field and SteadyState Ocean Circulation Explorer Satellite Mission Its Impact on Geophysics, Surv. Geophys., 24, 339-386, https://doi.org/10.1023/B:GEOP.0000004264.04667.5e, 2003.

Johannessen, J. A., Raj, R. P., Nilsen, J. E. Ø., Pripp, T., Knudsen, P., Counillon, F., Stammer, D., Bertino, L., Andersen, O. B., Serra, N., and Koldunov, N.: Toward Improved Estimation of the Dynamic Topography and Ocean Circulation in the High Latitude and Arctic Ocean: The Importance of GOCE, Surv. Geophys., 35, 661-679, https://doi.org/10.1007/s10712-013-9270-y, 2014.

Klees, R., Slobbe, D. C., and Farahani, H. H.: A Methodology for Least-Squares Local Quasi-Geoid Modelling Using a Noisy Satellite-Only Gravity Field Model, J. Geodesy, 92, 431-442, https://doi.org/10.1007/s00190-017-1076-0, 2018.

Klinger, B. and Mayer-Gürr, T.: The role of accelerometer data calibration within GRACE gravity field recovery: Results from ITSG-Grace2016, Adv. Space Res., 58, 1597-1609, https://doi.org/10.1016/j.asr.2016.08.007, 2016.

Knocke, P. C., Ries, J. C., and Tapley, B. D.: Earth radiation pressure effects on satellites, in: Astrodynamics Conference, 1988 , Guidance, Navigation, and Control and Co-located Conferences, American Institute of Aeronautics and Astronautics, 577-587, https://doi.org/10.2514/6.1988-4292, 1988.

Knudsen, P., Bingham, R., Andersen, O., and Rio, M.-H.: A Global Mean Dynamic Topography and Ocean Circulation Estimation Using a Preliminary GOCE Gravity Model, J. Geodesy, 85, 861879, https://doi.org/10.1007/s00190-011-0485-8, 2011.

Koch, K. R. and Kusche, J.: Regularization of geopotential determination from satellite data by variance components, J. Geodesy, 76, 259-268, https://doi.org/10.1007/s00190-002-0245-x, 2002.

Kornfeld, R. P., Arnold, B. W., Gross, M. A., Dahya, N. T., Klipstein, W. M., Gath, P. F., and Bettadpur, S.: 
GRACE-FO: The Gravity Recovery and Climate Experiment Follow-On Mission, J. Spacecraft Rockets, 56, 931-951, https://doi.org/10.2514/1.A34326, 2019.

Kvas, A., Behzadpour, S., Ellmer, M., Klinger, B., Strasser, S., Zehentner, N., and Mayer-Gürr, T.: ITSG-Grace2018: Overview and evaluation of a new GRACE-only gravity field time series, J. Geophys. Res.-Sol. Ea., 124, 9332-9344, https://doi.org/10.1029/2019JB017415, 2019a.

Kvas, A., Mayer-Gürr, T., Krauss, S., Brockmann, J. M., Schubert, T., Schuh, W.-D., Pail, R., Gruber, T., Jäggi, A., and Meyer, U.: The satellite-only gravity field model GOCO06s, ICGEM, https://doi.org/10.5880/ICGEM.2019.002, 2019b.

Landerer, F. W., Flechtner, F. M., Save, H., Webb, F. H., Bandikova, T., Bertiger, W. I., Bettadpur, S. V., Byun, S. H., Dahle, C., Dobslaw, H., Fahnestock, E., Harvey, N., Kang, Z., Kruizinga, G. L. H., Loomis, B. D., McCullough, C., Murböck, M., Nagel, P., Paik, M., Pie, N., Poole, S., Strekalov, D., Tamisiea, M. E., Wang, F., Watkins, M. M., Wen, H.-Y., Wiese, D. N., and Yuan, D.-N.: Extending the Global Mass Change Data Record: GRACE Follow-On Instrument and Science Data Performance, Geophys. Res. Lett., 47, e2020GL088306, https://doi.org/10.1029/2020GL088306, 2020.

Lemoine, F. G., Goossens, S., Sabaka, T. J., Nicholas, J. B., Mazarico, E., Rowlands, D. D., Loomis, B. D., Chinn, D. S., Caprette, D. S., Neumann, G. A., Smith, D. E., and Zuber, M. T.: High-degree gravity models from GRAIL primary mission data, J. Geophys. Res.-Planets, 118, 1676-1698, https://doi.org/10.1002/jgre.20118, 2013.

Lück, C., Kusche, J., Rietbroek, R., and Löcher, A.: Timevariable gravity fields and ocean mass change from 37 months of kinematic Swarm orbits, Solid Earth, 9, 323-339, https://doi.org/10.5194/se-9-323-2018, 2018.

Maier, A., Krauss, S., Hausleitner, W., and Baur, O.: Contribution of Satellite Laser Ranging to Combined Gravity Field Models, Adv. Space Res., 49, 556-565, https://doi.org/10.1016/j.asr.2011.10.026, 2012.

Mayer-Gürr, T.: Gravitationsfeldbestimmung Aus Der Analyse Kurzer Bahnbögen Am Beispiel Der Satellitenmissionen CHAMP Und GRACE, PhD thesis, University of Bonn, Bonn, Germany, available at: http://nbn-resolving.de/urn:nbn:de:hbz: 5N-09047 (last access: 20 January 2021), 2006.

Mayer-Gürr, T., Pail, R., Gruber, T., Fecher, T., Rexer, M., Schuh, W.-D., Kusche, J., Brockmann, J.-M., Rieser, D., Zehentner, N., Kvas, A., Klinger, B., Baur, O., Höck, E., Krauss, S., and Jäggi, A.: The Combined Satellite Gravity Field Model GOCO05S (Abstract), in: EGU General Assembly Conference Abstracts, 17, EGU2015-12364, Vienna, Austria, 2015.

Mayer-Gürr, T., Behzadpur, S., Ellmer, M., Kvas, A., Klinger, B., Strasser, S., and Zehentner, N.: ITSG-Grace2018 - Monthly and Daily Gravity Field Solutions from GRACE, ICGEM, https://doi.org/10.5880/icgem.2018.003, 2018.

Mayer-Gürr, T., Behzadpur, S., Ellmer, M., Kvas, A., Klinger, B., Strasser, S., and Zehentner, N.: ITSG-Grace2018 - Monthly, Daily and Static Gravity Field Solutions from GRACE, ICGEM, https://doi.org/10.5880/icgem.2018.003, 2018a.

Mayer-Gürr, T., Behzadpur, S., Ellmer, M., Kvas, A., Klinger, B., Strasser, S., and Zehentner, N.: ITSG-Grace2018 - Monthly, Daily and Static Gravity Field Solutions from GRACE, ICGEM, https://doi.org/10.5880/icgem.2018.003, 2018b.
Meyer, U., Jäggi, A., Jean, Y., and Beutler, G.: AIUBRL02: An improved time-series of monthly gravity fields from GRACE data, Geophys. J. Int., 205, 1196-1207, https://doi.org/10.1093/gji/ggw081, 2016.

Meyer, U., Jean, Y., Kvas, A., Dahle, C., Lemoine, J., and Jäggi, A.: Combination of GRACE monthly gravity fields on the normal equation level, J. Geodesy, 93, 1645-1658, https://doi.org/10.1007/s00190-019-01274-6, 2019.

Migliaccio, F., Reguzzoni, M., Gatti, A., Sansò, F., and Herceg, M.: A GOCE-Only Global Gravity Field Model by the Space-Wise Approach, in: Proceedings of the 4th International GOCE User Workshop, ESA Publication SP-696, edited by: Ouwehand, L., ESA/ESTEC, 2011.

Montenbruck, O. and Gill, E.: Satellite Orbits: Models, Methods, and Applications, Springer, Berlin, New York, 2000.

Neeck, S. P. and Vaze, P. V.: The Ocean Surface Topography Mission (OSTM), Proc. SPIE, 7106, 710603, https://doi.org/10.1117/12.803677, 2008.

Pail, R., Goiginger, H., Schuh, W.-D., Höck, E., Brockmann, J. M., Fecher, T., Gruber, T., Mayer-Gürr, T., Kusche, J., Jäggi, A., and Rieser, D.: Combined Satellite Gravity Field Model GOCO01S Derived from GOCE and GRACE, Geophys. Res. Lett., 37, L20314, https://doi.org/10.1029/2010GL044906, 2010.

Pail, R., Bruinsma, S., Migliaccio, F., Förste, C., Goiginger, H., Schuh, W.-D., Höck, E., Reguzzoni, M., Brockmann, J. M., Abrikosov, O., Veicherts, M., Fecher, T., Mayrhofer, R., Krasbutter, I., Sansò, F., and Tscherning, C. C.: First GOCE Gravity Field Models Derived by Three Different Approaches, J. Geodesy, 85, 819, https://doi.org/10.1007/s00190-011-0467-x, 2011.

Pail, R., Gruber, T., Fecher, T., and GOCO Project Team: The Combined Gravity Model GOCO05c, https://doi.org/10.5880/icgem.2016.003, ICGEM, 2016.

Pail, R., Fecher, T., Barnes, D., Factor, J. F., Holmes, S. A., Gruber, T., and Zingerle, P.: Short Note: The Experimental Geopotential Model XGM2016, J. Geodesy, 92, 443-451, https://doi.org/10.1007/s00190-017-1070-6, 2018.

Panet, I., Bonvalot, S., Narteau, C., Remy, D., and Lemoine, J.M.: Migrating pattern of deformation prior to the Tohoku-Oki earthquake revealed by GRACE data, Nat. Geosci., 11, 367-373, https://doi.org/10.1038/s41561-018-0099-3, 2018.

Pavlis, N. K., Holmes, S. A., Kenyon, S. C., and Factor, J. K.: The Development and Evaluation of the Earth Gravitational Model 2008 (EGM2008), J. Geophys. Res.-Sol. Ea., 117, B04406, https://doi.org/10.1029/2011JB008916, 2012.

Petit, G. and Luzum, B.: IERS Conventions (2010), Technical Note 36, International Earth Rotation and Reference Systems Service, Frankfurt am Main, 2010.

Reigber, C., Schwintzer, P., and Lühr, H.: The CHAMP Geopotential Mission, Bolletino di Geofisica Teorica ed Applicata, 40, 285-289, 1999.

Reigber, C., Balmino, G., Schwintzer, P., Biancale, R., Bode, A., Lemoine, J.-M., König, R., Loyer, S., Neumayer, H., Marty, J.-C., Barthelmes, F., Perosanz, F., and Zhu, S. Y.: Global Gravity Field Recovery Using Solely GPS Tracking and Accelerometer Data from Champ, Space Sci. Rev., 108, 55-66, https://doi.org/10.1023/A:1026217713133, 2003.

Rio, M.-H., Mulet, S., and Picot, N.: Beyond GOCE for the Ocean Circulation Estimate: Synergetic Use of Altimetry, Gravimetry, and in Situ Data Provides New Insight into Geostrophic 
and Ekman Currents, Geophys. Res. Lett., 41, 2014GL061773, https://doi.org/10.1002/2014GL061773, 2014.

Rudenko, S., Dettmering, D., Esselborn, S., Schöne, T., Förste, C., Lemoine, J.-M., Ablain, M., Alexandre, D., and Neumayer, K.-H.: Influence of Time Variable Geopotential Models on Precise Orbits of Altimetry Satellites, Global and Regional Mean Sea Level Trends, Adv. Space Res., 54, 92-118, https://doi.org/10.1016/j.asr.2014.03.010, 2014.

Rummel, R.: Height Unification Using GOCE, Journal of Geodetic Science, 2, 355-362, https://doi.org/10.2478/v10156-011-00472, 2013.

Rummel, R. and Colombo, O. L.: Gravity Field Determination from Satellite Gradiometry, Bulletin géodésique, 59, 233-246, https://doi.org/10.1007/BF02520329, 1985.

Rummel, R., Balmino, G., Johannessen, J., Visser, P., and Woodworth, P.: Dedicated Gravity Field Missions - Principles and Aims, J. Geodynamics, 33, 3-20, https://doi.org/10.1016/S02643707(01)00050-3, 2002.

Rummel, R., Horwath, M., Yi, W., Albertella, A., Bosch, W., and Haagmans, R.: GOCE, Satellite Gravimetry and Antarctic Mass Transports, Surv. Geophys., 32, 643-657, https://doi.org/10.1007/s10712-011-9115-5, 2011a.

Rummel, R., Yi, W., and Stummer, C.: GOCE Gravitational Gradiometry, J. Geodesy, 85, 777, https://doi.org/10.1007/s00190011-0500-0, 2011b.

Save, H., Bettadpur, S., and Tapley, B. D.: High-resolution CSR GRACE RL05 mascons, J. Geophys. Res.-Sol. Ea., 121, 75477569, https://doi.org/10.1002/2016JB013007, 2016

Schall, J., Eicker, A., and Kusche, J.: The ITG-Goce02 Gravity Field Model from GOCE Orbit and Gradiometer Data Based on the Short Arc Approach, J. Geodesy, 88, 403-409, https://doi.org/10.1007/s00190-014-0691-2, 2014.

Schubert, T., Brockmann, J. M., and Schuh, W.-D.: Identification of Suspicious Data for Robust Estimation of Stochastic Processes, in: IX Hotine-Marussi Symposium, International Association of Geodesy Symposia, Springer, 1-9, https://doi.org/10.1007/1345_2019_80, 2019.

Seo, K. W., Wilson, C. R., Han, S. C., and Waliser, D. E.: Gravity Recovery and Climate Experiment (GRACE) alias error from ocean tides, J. Geophys. Res.-Sol. Ea., 113, B03405, https://doi.org/10.1029/2006JB004747, 2008.

Siegismund, F.: Assessment of Optimally Filtered Recent Geodetic Mean Dynamic Topographies, J. Geophys. Res.-Oceans, 118, 108-117, https://doi.org/10.1029/2012JC008149, 2013.

Siemes, C., Haagmans, R., Kern, M., Plank, G., and Floberghagen, R.: Monitoring GOCE Gradiometer Calibration Parameters Using Accelerometer and Star Sensor Data: Methodology and First Results, J. Geodesy, 86, 629-645, https://doi.org/10.1007/s00190-012-0545-8, 2012.

Siemes, C., Rexer, M., Schlicht, A., and Haagmans, R.: GOCE Gradiometer Data Calibration, J. Geodesy, 93, 1603-1630, https://doi.org/10.1007/s00190-019-01271-9, 2019.

Slobbe, C., Klees, R., H. Farahani, H., Huisman, L., Alberts, B., Voet, P., and Doncker, F. D.: The Impact of Noise in a GRACE/GOCE Global Gravity Model on a Local Quasi-Geoid, J. Geophys. Res.-Sol. Ea., 124, 3219-3237, https://doi.org/10.1029/2018JB016470, 2019.

Sneeuw, N.: Global spherical harmonic analysis by least-squares and numerical quadrature methods in historical perspective,
Geophys. J. Int., 118, 707-716, https://doi.org/10.1111/j.1365246X.1994.tb03995.x, 1994.

Sneeuw, N. and van Gelderen, M.: The polar gap, in: Geodetic Boundary Value Problems in View of the One Centimeter Geoid, edited by: Sansó, F. and Rummel, R., Springer Berlin Heidelberg, Berlin, Heidelberg, 559-568, https://doi.org/10.1007/BFb0011717, 1997.

Sośnica, K., Jäggi, A., Meyer, U., Thaller, D., Beutler, G., Arnold, D., and Dach, R.: Time Variable Earth's Gravity Field from SLR Satellites, J. Geodesy, 89, 945-960, https://doi.org/10.1007/s00190-015-0825-1, 2015.

Stummer, C., Siemes, C., Pail, R., Frommknecht, B., and Floberghagen, R.: Upgrade of the GOCE Level 1b Gradiometer Processor, Adv. Space Res., 49, 739-752, https://doi.org/10.1016/j.asr.2011.11.027, 2012.

Tapley, B. D., Bettadpur, S., Ries, J. C., Thompson, P. F., and Watkins, M. M.: GRACE Measurements of Mass Variability in the Earth System, Science, 305, 503-505, https://doi.org/10.1126/science.1099192, 2004.

Tapley, B. D., Watkins, M. M., Flechtner, F., Reigber, C., Bettadpur, S., Rodell, M., Sasgen, I., Famiglietti, J. S., Landerer, F. W., Chambers, D. P., Reager, J. T., Gardner, A. S., Save, H., Ivins, E. R., Swenson, S. C., Boening, C., Dahle, C., Wiese, D. N., Dobslaw, H., Tamisiea, M. E., and Velicogna, I.: Contributions of GRACE to understanding climate change, Nat. Clim. Change, 9, 358-369, https://doi.org/10.1038/s41558-019-0456-2, 2019.

Teixeira da Encarnação, J., Arnold, D., Bezděk, A., Dahle, C., Doornbos, E., van den IJssel, J., Jäggi, A., Mayer-Gürr, T., Sebera, J., Visser, P., and Zehentner, N.: Gravity Field Models Derived from Swarm GPS Data, Earth Planet. Space, 68, 127, https://doi.org/10.1186/s40623-016-0499-9, 2016.

Teixeira da Encarnação, J., Visser, P., Arnold, D., Bezdek, A., Doornbos, E., Ellmer, M., Guo, J., van den IJssel, J., Iorfida, E., Jäggi, A., Klokocník, J., Krauss, S., Mao, X., Mayer-Gürr, T., Meyer, U., Sebera, J., Shum, C. K., Zhang, C., Zhang, Y., and Dahle, C.: Description of the multi-approach gravity field models from Swarm GPS data, Earth Syst. Sci. Data, 12, 1385-1417, https://doi.org/10.5194/essd-12-1385-2020, 2020.

Vergos, G. S., Erol, B., Natsiopoulos, D. A., Grigoriadis, V. N., Isik, M. S., and Tziavos, I. N.: Preliminary Results of GOCE-Based Height System Unification between Greece and Turkey over Marine and Land Areas, Acta Geod. Geophys., 53, 61-79, https://doi.org/10.1007/s40328-017-0204-x, wOS:000429387700005, 2018.

Wahr, J., Molenaar, M., and Bryan, F.: Time variability of the Earth's gravity field: Hydrological and oceanic effects and their possible detection using GRACE, J. Geophys. Res.-Sol. Ea., 103, 30205-30229, https://doi.org/10.1029/98JB02844, 1998.

Yi, W.: An Alternative Computation of a Gravity Field Model from GOCE, Adv. Space Res., 50, 371-384, https://doi.org/10.1016/j.asr.2012.04.018, 2012.

Yi, W., Rummel, R., and Gruber, T.: Gravity Field Contribution Analysis of GOCE Gravitational Gradient Components, Stud. Geophys. Geod., 57, 174-202, https://doi.org/10.1007/s11200011-1178-8, 2013.

Zehentner, N. and Mayer-Gürr, T.: Precise orbit determination based on raw GPS measurements, J. Geodesy, 90, 275-286, https://doi.org/10.1007/s00190-015-0872-7, 2016. 
Zingerle, P., Pail, R., Gruber, T., and Oikonomidou, X.: The Experimental Gravity Field Model XGM2019e, ICGEM, https://doi.org/10.5880/ICGEM.2019.007, 2019.
Zingerle, P., Pail, R., Gruber, T., and Oikonomidou, X.: The Combined Global Gravity Field Model XGM2019e, J. Geodesy, 94, 66, https://doi.org/10.1007/s00190-020-01398-0, 2020. 